\title{
Energy Conservation Strategies for Windows and Glazed Surfaces
}

by

Brian M. Deal, Robert J. Nemeth, and Lee P. DeBaille

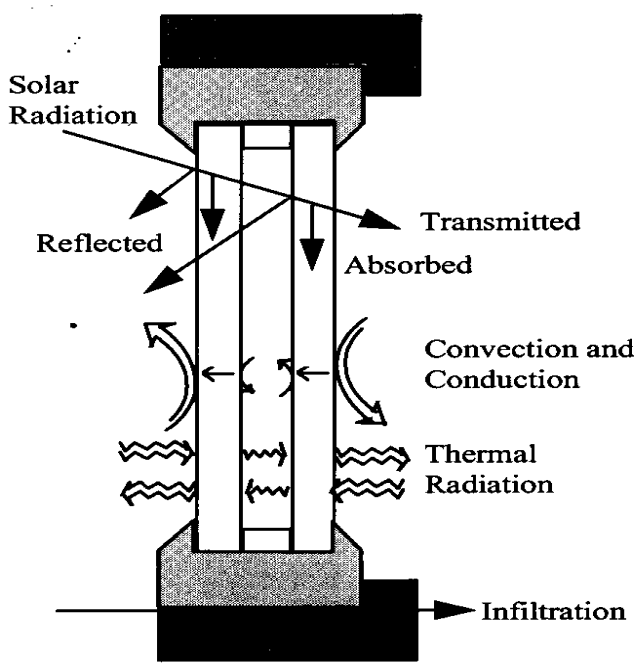

Technological advances in glazing and window assemblies, lighting, and energy management controls have complicated glazing systems design. Selecting a window assembly that provides the greatest value or efficiency is difficult considering the multitude of performance criteria that should be considered, the many available glazing options, and the profusion of window manufacturers in the marketplace.

To address this problem, this report synthesizes up-to-date information on basic conservation strategies that relate to the design and specification of glazing and window assemblies. General concepts of building fenestration design and the role of the design professional in the selection of glazing systems are introduced. Information on heat transfer dynamics relating to glazed surfaces is presented and technological advances in glazing and window assemblies are discussed. Methods for the selection of glazing systems are also presented in the form of case studies, and a general discussion of window labeling and technical sources for information are presented.

The report also provides design professionals, specifiers, and energy managers with references and sources for additional technical information on windows, glazing products, and issues surrounding new glazing technologies. 


\section{Foreword}

This study was conducted for the Directorate of Military Programs, Headquarters, U.S. Army Corps of Engineers (HQUSACE) under Project 4A162784AT45, "Energy and Energy Conservation"; Work Unit FL-X66, "Energy Efficient Envelope Strategies - 1996." The technical monitor was J oe McCarty, CEMP-ET.

The work was performed by the Engineering Division (FL-E) of the Facilities Technology Laboratory (FL), U.S. Army Construction Engineering Research Laboratories (USACERL). Larry M. Windingland is Acting Chief, CECER-FL-E, and L. Michael Golish is Acting Operations Chief, CECER-FL.

COL J ames A. Walter is Commander of USACERL and Dr. Michael J . O'Connor is Director. 


\section{Contents}

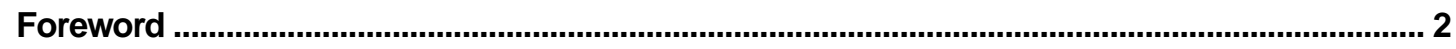

\section{List of Figures and Tables..................................................................................................... 5}

$1 \quad$ Introduction ................................................................................................................. 7

Background $\ldots \ldots \ldots \ldots \ldots \ldots \ldots \ldots \ldots \ldots \ldots \ldots \ldots \ldots \ldots \ldots \ldots \ldots \ldots \ldots \ldots \ldots \ldots \ldots \ldots \ldots \ldots \ldots \ldots \ldots \ldots \ldots \ldots \ldots \ldots \ldots$

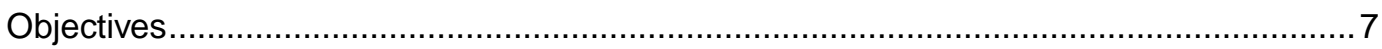

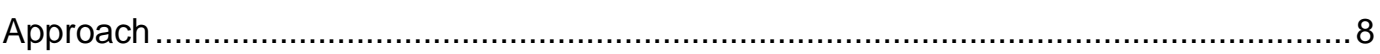

Scope $\ldots \ldots \ldots \ldots \ldots \ldots \ldots \ldots \ldots \ldots \ldots \ldots \ldots \ldots \ldots \ldots \ldots \ldots \ldots \ldots \ldots \ldots \ldots \ldots \ldots \ldots \ldots \ldots \ldots \ldots \ldots \ldots \ldots \ldots \ldots \ldots \ldots \ldots \ldots 8$

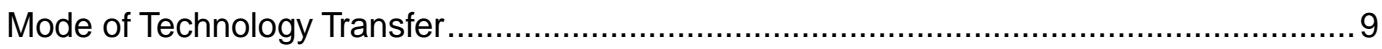

Metric Conversion Table $\ldots \ldots \ldots \ldots \ldots \ldots \ldots \ldots \ldots \ldots \ldots \ldots \ldots \ldots \ldots \ldots \ldots \ldots \ldots \ldots \ldots \ldots \ldots \ldots \ldots \ldots 9$

$2 \quad$ Building Design and Fenestration ........................................................................ 10

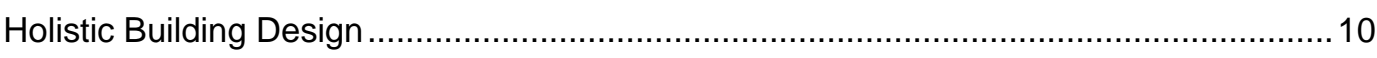

Fenestration Design $\ldots \ldots \ldots \ldots \ldots \ldots \ldots \ldots \ldots \ldots \ldots \ldots \ldots \ldots \ldots \ldots \ldots \ldots \ldots \ldots \ldots \ldots \ldots \ldots \ldots \ldots \ldots 12$

$3 \quad$ Heat Transfer Fundamentals .................................................................................... 14

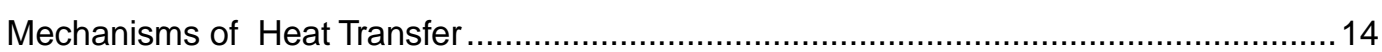

Heat Transfer Process Through Glass $\ldots \ldots \ldots \ldots \ldots \ldots \ldots \ldots \ldots \ldots \ldots \ldots \ldots \ldots \ldots \ldots \ldots \ldots \ldots \ldots \ldots 16$

Solar Heat Gain $\ldots \ldots \ldots \ldots \ldots \ldots \ldots \ldots \ldots \ldots \ldots \ldots \ldots \ldots \ldots \ldots \ldots \ldots \ldots \ldots \ldots \ldots \ldots \ldots \ldots \ldots \ldots \ldots \ldots \ldots \ldots 18$



Ultraviolet Protection $\ldots \ldots \ldots \ldots \ldots \ldots \ldots \ldots \ldots \ldots \ldots \ldots \ldots \ldots \ldots \ldots \ldots \ldots \ldots \ldots \ldots \ldots \ldots \ldots \ldots \ldots \ldots 29$

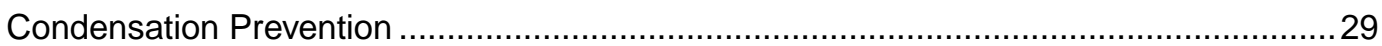

$4 \quad$ Glazing Technologies ...................................................................................................... 32

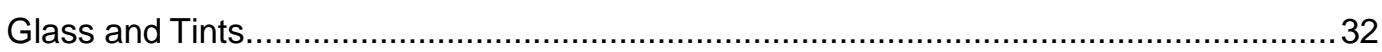



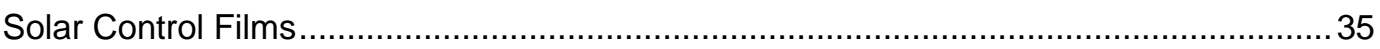

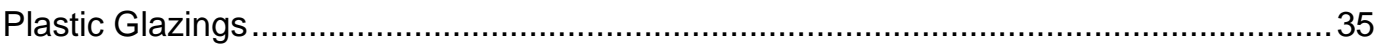



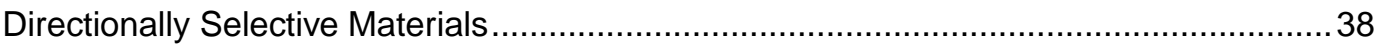

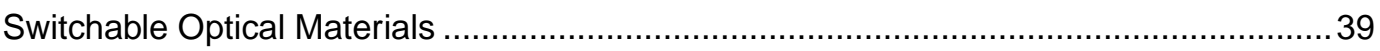

5 Window Assemblies......................................................................................................... 41






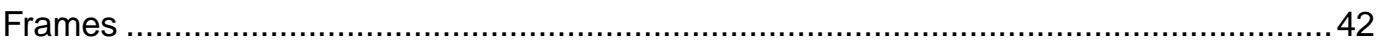



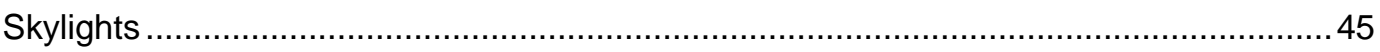

$6 \quad$ Fenestration Economics ............................................................................................... 47

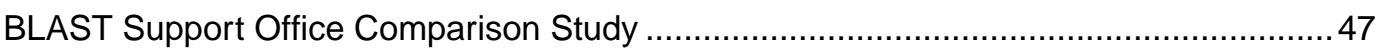

ENSAR Reglazing Analysis Case Study ................................................................ 51

$7 \quad$ Window Energy Rating and Labeling ...........................................................................62



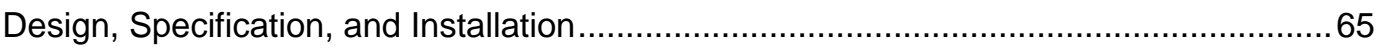

Insulating Value and Condensation Resistance ......................................................6

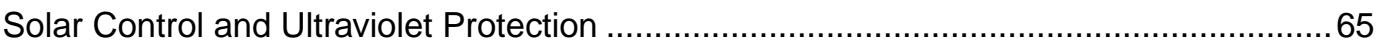

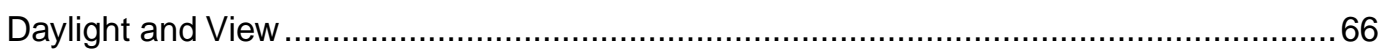

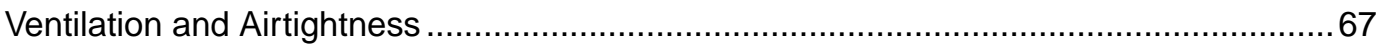

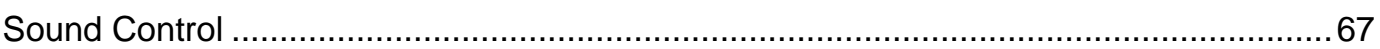

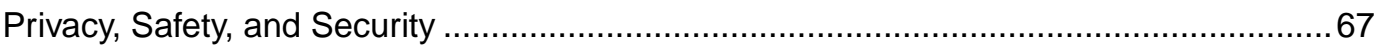

Maintenance, Durability, and Lifetime ……………................................................... 68

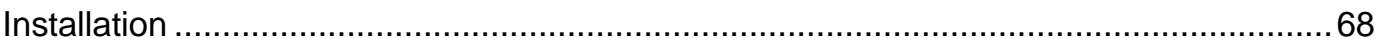

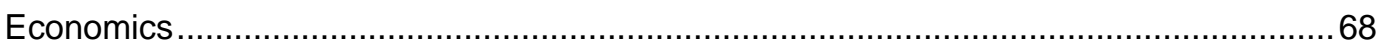

9 Conclusions and Recommendations ..............................................................................6

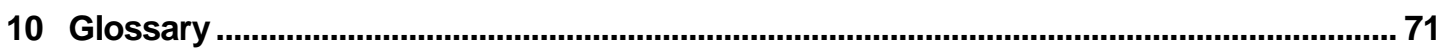

Appendix A: Information Source List ................................................................ 73

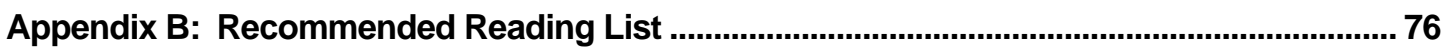

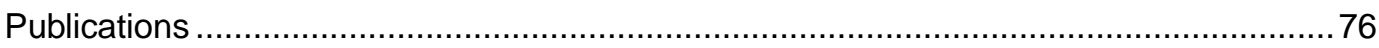

Internet Sources ........................................................................................... 76

\section{Distribution}




\section{List of Figures and Tables}

Figures

1 Mbdes of radiation for a typical wood window section. …........................................17

2 The solar spectrum................................................................................. 19

3 Energy intesity and wavelength. ...................................................................... 20

4 Effects of light on glass. ..................................................................................... 21

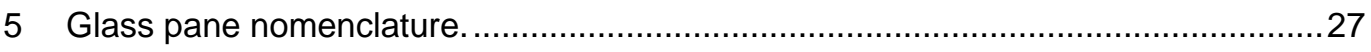

6 Conditions for window condensation. ..................................................................... 31



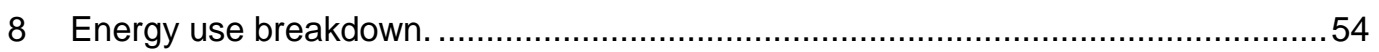

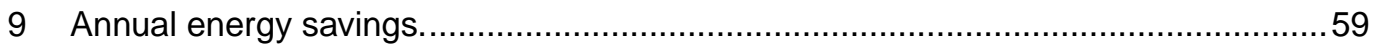

10 Installed glazing cost.........................................................................6

11 Ten-year life cycle cost............................................................................... 60

12 Twenty-year life cycle cost. ............................................................................... 61

13 Sample of NFRC rating label ................................................................... 64

\section{Tables}

1 Physical and optical properties of sample configurations.........................................

2 Representative window solar heat gain coefficients and visible transmittances ${ }^{*} \ldots \ldots . .26$

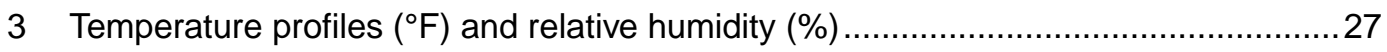

4 Representative window U-Factors (Btu/hr •ft $\left.{ }^{2}{ }^{\circ} \mathrm{F}\right)$..................................................4

5 Weather regions/locations (U.S. Department of Energy) for BSO study ....................49



$7 \quad$ Present worth of 10 years of energy savings per $100 \mathrm{ft}^{2}$ of glazing.............................5

8 Baseline condition (ENSAR case study) .........................................................

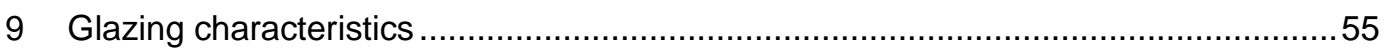

10 Energy performance-compared with existing conditions ................................56

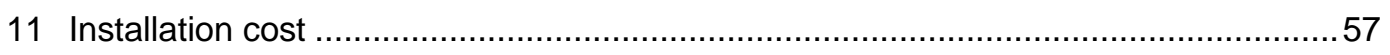

12 Simple life-cycle analysis ....................................................................... 58

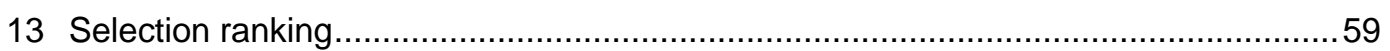




\section{Introduction}

\section{Background}

Technological advances in glazing and window assemblies, lighting, and sophisticated energy management controls have complicated glazing systems design. Selecting a window assembly that provides the greatest value or efficiency is difficult considering the multitude of performance criteria that should be considered and evaluated, the number of glazing options to select from, and the profusion of window manufactures on the market.

Windows are defined as the physical openings in a building's exterior envelope. The resulting pattern of the openings is considered fenestration design. Typically provided for natural light, ventilation, and view related purposes, these openings also contribute both positively and negatively to a building's overall performance. This correlation between windows and building performance, coupled with an increasing awareness of resource conservation measures, requires that fenestration schemes be looked at critically, early in the design process.

The evaluation of fenestration alternatives is a complex problem. Design tools are available to aid in the analysis, but they are no substitute for informed designers.

Window and glazing product selection during the preliminary design phase can have profound repercussions throughout the life of a building. Information that helps designers and specifiers to optimize the selection of building components can enhance the functionality of a building, and subsequently reduce its burden on the environment.

\section{Objectives}

The objective of this project was to provide a comprehensive document on windows and glazing technologies that can be used by design professionals, 
specifiers, and energy managers to improve the window and glazing selection process.

\section{Approach}

This report synthesizes current information on windows and glazing products, and discusses the issues surrounding new glazing technologies, including the following:

1. review of publicly financed research on window and glazing systems

2. research of current publications on glazing and computer-based building design tools

3. the Glazing Design Handbook by the ENSAR Group, Inc. (funded by the U.S. Army Construction Engineering Research Laboratories (USACERL), Southern California Edison, and the American Institute of Architects (AIA)

4. research using the Building Loads Analysis and System Thermodynamics (BLAST) program to compare glazing types and associated costs (funded by USACERL, the University of Illinois, and the BLAST Support Office at the University of Illinois Mechanical Engineering Department)

\section{Scope}

This report represents background information on the current state of window and glazing technologies. It also presents preliminary design issues that should be addressed in the analysis of fenestration systems and can serve as a source of information for further contacts regarding glazing design issues.

This report examines several issues regarding the design and selection of windows and glazing systems 1 ]

\footnotetext{
1 It should be recognized that fenestration design is a subset of building design, and therefore is very context sensitive. Unless multiple buildings are being built in the same geographic region, on the same site, with the same orientation, a separate analysis should be conducted for each individual building design.
} 
- design concepts

- heat transfer basics

- glazing technologies and window assemblies

- window selection and rating issues.

\section{Mode of Technology Transfer}

Information from this study will be submitted for publication by the U.S. Army Center for Public Works in the DPW Digest. Presentations of this material will be made at Energy Awareness Seminars and Energy Managers' Conference Seminars.

\section{Metric Conversion Table}

U.S. standard units of measure are used throughout this report. A table of conversion factors for Standard International (SI) units is provided below.

\begin{tabular}{l}
\multicolumn{3}{l|}{ SI conversion factors } \\
\begin{tabular}{|lll}
$1 \mathrm{in}$. & $=$ & $25.4 \mathrm{~cm}$ \\
$1 \mathrm{ft}$ & $=$ & $0.305 \mathrm{~m}$ \\
$1 \mathrm{sq} \mathrm{in.}$ & $=$ & $6.452 \mathrm{~cm}^{2}$ \\
$1 \mathrm{sq} \mathrm{ft}$ & $=$ & $0.093 \mathrm{~m}^{2}$ \\
${ }^{\circ} \mathrm{F}$ & $=$ & $\left({ }^{\circ} \mathrm{C} \times 1.8\right)+32$ \\
\hline
\end{tabular}
\end{tabular}




\section{Building Design and Fenestration}

The design of a structure for human occupation is a complex task. It involves functional, structural, and mechanical relationships that require the coordination of many expert disciplines. Building material advances, systems advances, and the development of sophisticated computer modeling techniques can expand and enhance potential design solutions. Advanced design solutions require detailed analysis in order to identify material and performance optimization criteria. This identification process is difficult to complete.

\section{Holistic Building Design}

The traditional methodology for the product design and delivery process of a building typically includes the architect, who independently completes the initial stages of design; a host of engineers and consultants who "cram and jam" component systems into the architect's design solution; and a return to the architect for coordination and assembly of final documentation and contract administration. This type of inefficient and uncoordinated design delivery process is slowly being replaced by an integrated team approach.

An integrated, or holistic design approach includes engineers, planners, and other consultants during the early planning and preliminary design phase. The early involvement of all required disciplines allows for a more integrated building design. It encourages early, open dialogue toward a "site-specific" design through an iterative process involving the various disciplines at the design phase.

Introducing feedback loops into the design process can impact building envelope and fenestration design. The holistic design approach more readily recognizes the vital interaction that takes place between individual building systems. Each building component is more likely to be viewed as a part of a larger whole and not as a separate entity, greatly improving building performance. For example, the optimization of a structure's fenestration design can have a ripple effect on many other building component systems. 
The following scenario is a hypothetical building, designed by optimizing the fenestration system to achieve maximum, overall building energy efficiency.

\section{Design solution: Daylighting optimization}

Effect:

- reduced energy consumption due to reduced artificial lighting system run-time

- reduced electrical demand due to reduced lighting load during peak hours

- reduced cooling load on mechanical system due to reduced lighting loads

- a possible increased cooling load from daylighting fenestration system (a net cooling load reduction can be achieved through the use of spectrally selective windows)

Mechanical implications resulting from optimizing glazed surfaces:

- smaller chiller plant and reduced run-time

- smaller cooling tower

- smaller distribution system due to load reductions

- smaller heating plant and reduced run-time

- smaller mechanical room requirements

Cost implications:

- increased design costs

- reduced utility costs (energy and demand)-from lighting and heating, ventilation and air-conditioning (HVAC)

- reduced capital cost of HVAC equipment 
- possible increase in the capital cost of lighting system

Modifying the process to accommodate early feedback loops can provide great benefits. Typical obstacles to using this approach include:

- holistic design is a more complicated approach and constitutes a significant break from traditional design;

- holistic design requires more analysis from the design team;

- frequently there is no financial incentive for the design team to provide this type of approach;

- the holistic design process requires specialized capabilities that may include the ability to use sophisticated computer software;

- holistic design requires the architect and owner to involve other disciplines early in the design process.

\section{Fenestration Design}

\section{Components}

The term "fenestration" describes the physical arrangement of openings in a building's exterior envelope. This typically involves the design and disposition of window assemblies and doors. Component parts of a window assembly include frame, sash, glazing, spacers, and any accompanying hardware. Glazing describes the transparent or translucent component of the window assembly.

As noted previously, the fenestration design of a building can have a quantifiable impact on the energy performance characteristics of a building. It can also have an identifiable impact on the performance of a building's occupants. Designbehavior research has explored the effects on workers of various elements of workplace environments, such as lighting conditions, noise levels, views from windows, and office furniture arrangements. Such research has focused on the qualitative aspects of the work environment and on workers' perceptions of their surroundings. The quantification of potential gains in worker productivity, however, is difficult and context dependent. 
Conversely, the potential energy use impacts of a structure are easily identified and quantified through simulation modeling techniques and can be confirmed through empirical validation. This report focuses on the quantifiable issues related to the fenestration design of a building.

\section{Windows and Glazing}

A brief examination into the historical development of windows reveals that the most basic function of a window opening is for the introduction of natural light and ventilation into the interior of a structure. The advent of clean and efficient mechanical systems has diminished one functional component, ventilation, by reducing natural ventilation requirements. Likewise, the improvement of artificial light sources has decreased the necessity for natural daylighting.

As environmental systems that control, modify, or simulate natural processes improve, the design parameters for windows and glazing systems are modified. In the 1970s, window design was focused toward mitigating unwanted solar heat gains and increasing window insulating abilities in response to the energy crisis. In the 1990's, the advancement of control technologies has encouraged a new building design paradigm of "smart" systems and neural networks that physically interact to provide comfortable interior spaces. For example, lighting systems can now be configured to automatically modulate depending on the amount of natural light within a space.

Improvements in fenestration system components (advanced glazings, improved glass coating and edge sealing techniques, suspended films, improved window frames, and sealant technologies) have substantially altered how windows function and impact interior spaces. However, these technological advances have not substantially altered the window's basic, historic function, and windows are once again being recognized for their daylighting abilities and their potential to provide energy savings and fresh air. 


\section{Heat Transfer Fundamentals}

This section reviews basic heat transfer fundamentals as they relate to glazing technology, specification, and performance.

\section{Mechanisms of Heat Transfer}

Heat transfer is the movement of energy that results from a temperature differential. The three basic mechanisms, or modes, of heat transfer are conduction, convection, and radiation.

\section{Conduction}

In general, conduction is the flow of energy across a solid, gas, or liquid due to thermal diffusion between molecules. An everyday example is a pot on a stove becoming hot after contact with the burner. Molecules vibrate according to their energy level (temperature), and this energy is transferred from molecule to molecule through the solid from higher to lower temperatures. The amount of energy transferred by conduction is directly proportional to the temperature difference (referred to as $-\mathrm{T}$ or "delta- $\mathrm{T}$ ") and a material property called the thermal conductivity $(k)$. Conductive heat transfer is also inversely proportional to the thickness of the material $(\mathrm{L})$. These relationships to heat transfer $\left(\mathrm{Q}_{\text {cond }}\right)$ can be stated mathematically as

$$
\mathrm{Q}_{\text {cond }}=\mathrm{k}\left(\frac{\Delta \mathrm{T}}{\mathrm{L}}\right)
$$

[Eq 1]

For a given amount of heat transfer, a material that is very conductive (has a high k-value) or thin (small L) will be more effective at transferring thermal energy and will result in a lower temperature difference. Alternately, a material that is a good insulator (low k-value) or very thick (large $L$ ) will suppress heat transfer and will result in a larger temperature difference across the solid. 
Glass is a good conductor of thermal energy because of its relatively high $\mathrm{k}$ and low thickness ( $L)^{*}$ Air is a relatively poor conductor, which is why double-pane glazing (containing a blanket of air) provides additional insulation. The air acts as a thermal break to reduce thermal bridging between good conductors (the glazing panes). Some types of gas fills (argon) can further reduce the conductive properties of glass and often replace air in insulated glazing units.

\section{Convection}

Convective heat transfer is the term used to describe the heat transfer that occurs between a solid and a fluid, or a solid and a gas, at different temperatures. Convection consists of both conductive heat transfer and heat transfer resulting from the bulk motion of a fluid or gas. Convective heat transfer is directly proportional to the convection coefficient (h), which can be viewed as a measure of the ability of the fluid or gas to impart its thermal energy to or from the surface. As the h-value of a surface/fluid interface increases, the temperature of the surface will approach that of the fluid. The mathematical relationship for convective heat transfer $\left(Q_{\text {conv }}\right)$ is given below.

$$
Q_{\text {conv }}=h(\Delta T)
$$

Convection is dependent on many factors, the most important of which is the velocity of the fluid or gas over the solid surface. This is demonstrated by blowing on a hot object to cool it quickly before touching it. Convection can be further described as either natural or forced. Natural convection occurs when the motion of the gas or liquid is driven by differences in density (caused by temperature differentials within the entity). The force of gravity pulls the heavy fluid/gases down, which pushes the lighter fluid/gases up (that is, hot air rises, cool air falls). Forced convection is when the motion of the fluid or gas is externally induced (e.g., by a fan or the wind).

Heat transfer is usually higher for forced convection than for natural convection, because the vel ocity of the fluid/gas is often greater. Therefore, we blow on a hot object to cool it faster than the naturally rising hot air could. In typical glazing systems, convective heat transfer occurs between all gas/solid interfaces.

\footnotetext{
${ }^{*}$ For these reasons, metals are also excellent conductors.
} 


\section{Radiation}

Radiative heat transfer is the exchange of electromagnetic energy between surfaces of different temperatures. Radiative energy is emitted by any piece of matter that has a finite temperature. (A finite temperature is any temperature above absolute zero. Even very cold surfaces emit radiant energy, although very little.)

Physically, radiant energy leaves a surface via electromagnetic waves and travels until it is incident on another surface. If a surface "receives" more radiative energy than it "emits," its temperature will increase (omitting other forms of heat transfer), and vice-versa. One can experience a net positive radiative heat exchange when sitting near a wood-burning stove or radiant heater. The "heat" does not need air to travel through, and can in fact travel through empty space (e.g., sunlight). The equation that describes emitted radiation from a surface $\left(Q_{\text {enitted }}\right)$ is

$$
\mathrm{Q}_{\text {emitted }}=\varepsilon \sigma \mathrm{T}^{4}
$$

where $M=$ emissivity (a measure of a material's ability to emit radiant energy);

and $\left[=5.67 \times 10^{-8}\right.$ (a constant value)

For a given temperature, materials with high $M$ values radiate more effectively than those with small values.

\section{Heat Transfer Process Through Glass}

All surfaces emit radiant energy levels according to their mean temperature. That is, a high-temperature surface emits high levels of radiant energy; a lowtemperature surface emits low levels of radiant energy. From this fact it can be concluded that other nearby objects are also emitting their radiant energy back toward the surface in question. This incident radiant energy on a surface can be absorbed by the surface, reflected off the surface, or transmitted through the surface.

For glass, most of the incident radiant energy is transmitted through the surface, although reflection and absorption are also factors (their values being dependent upon the spectral properties of the glass type). These modes of 
radiation are illustrated in Figure 1 for a typical wood window section, along with other heat transfer modes.

The radiative energy exchange for the illustration is the net energy transferred from the warmer room surfaces to the cooler exterior surface of the glazing. Actually, both surfaces emit energy toward each other. However, since the room surfaces will be warmer than the glazing surfaces, the resultant net radiant heat transfer is from the room to the glazing. This does not consider the effects of incident sunlight from the outdoors, which may tip the balance.

In a separate process, convection also causes energy to be transferred from the warm interior air temperature to the glazing. Heat transfer then occurs across the glazing itself via conduction, and at the outdoor surface, convection and radiant emission again take over as the dominant modes of heat transfer, transferring thermal energy to the outdoors.

Infiltration can also be a factor in the heat transfer process of the above assembly. Infiltration is the exchange of air through cracks in the window assembly.

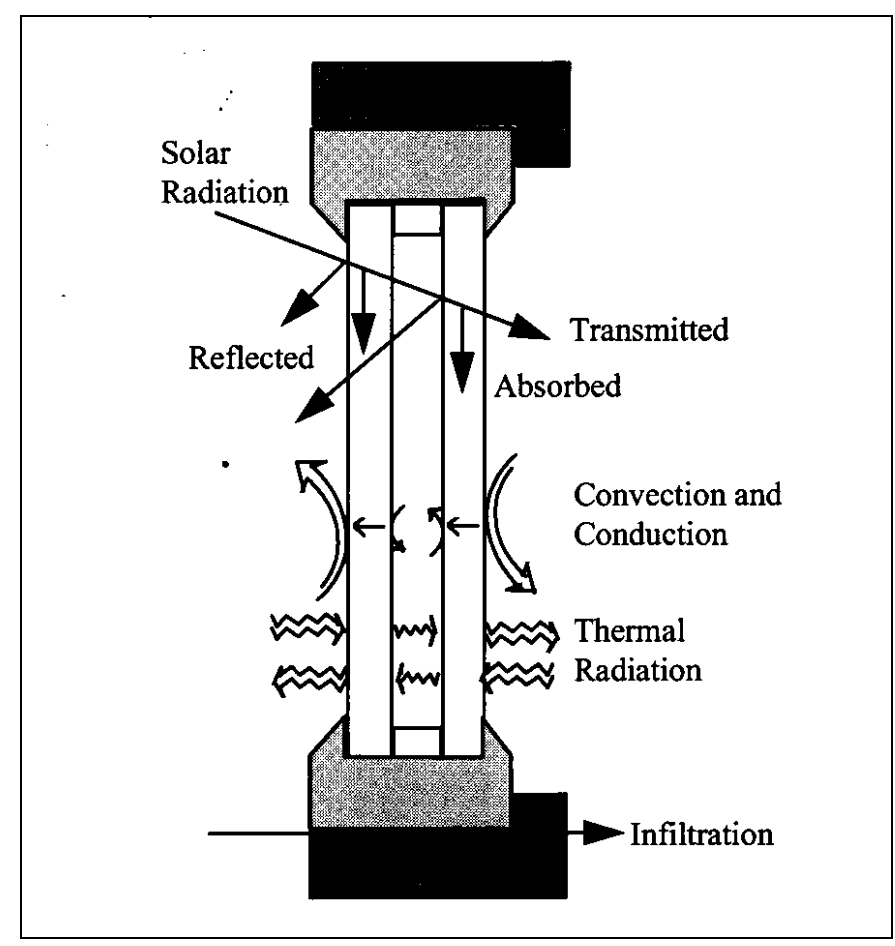

Figure 1. Modes of radiation for a typical wood window section. 
Along with the described modes of heat transfer, three glazing-related factors must be considered when evaluating the overall energy performance of a building:

1. interior glass surface temperature $\left(T_{\mathrm{gi}}\right)$

2. solar gain from incident sunlight coming through the window/glazing system

3. the ability of the window/glazing system to prevent infiltration.

These values will vary depending on some physical forces

- indoor and outdoor temperatures $\left(T_{i}\right.$ and $\left.T_{0}\right)$

- amount of incident solar radiation $\left(\mathrm{Q}_{\text {solar }}\right)$

- indoor and outdoor air pressure differential

- characteristics of the glazing (thermal properties, radiative properties, airtightness, etc).

The processes outlined above not only illustrate how energy is gained or lost through glazing, but are also important to understanding the performance of advanced glazing technologies. These technol ogies, which are discussed in more detail in Chapter 4, often involve material properties that enhance or suppress heat transfer, depending upon the design intent of the glazing system. To complete the discussion of the physics involved in glazing design, the properties of thermal radiation and the ways in which it contributes to solar gain are discussed in the following sections.

\section{Solar Heat Gain}

Solar radiation can be characterized by its wavelength, intensity, and direction. The visible and invisible portions of solar radiation can be identified within certain wavel ength regions or spectrums. The energy in solar radiation varies with wavelength, so that the amount of energy delivered within each spectrum differs. The majority of solar radiation energy exists in the wavelength spectrum between about 0.3 and $3.0 \mathrm{Tm}$, although some of it is attenuated in the earth's atmosphere. 
Figure 2 illustrates the different wavelengths that exist in the solar spectrum near the surface of the earth. The solar spectrum can be broken into three main groups: ultraviolet (UV), infrared, and visible light.

Ultraviolet energy is mostly invisible and embodies only about 7 percent of the energy in sunlight. Infrared energy is also invisible and contains about 46 percent of the energy in the solar spectrum. The visible spectrum contains about 47 percent of the energy in the solar spectrum. Figure 3 illustrates the relationship between energy intensity and wavelength in the three spectrums near the surface of the earth. Peak intensity is reached at about $0.45 \mathrm{Tm}$ in the green portion of the visible spectrum.

Solar heat gain is the measure of total heat gain (visible, infrared and UV) from sunlight that passes through a glazed surface and is eventually dissipated to the indoors. The amount of sunlight that a glazed surface receives is largely dependent on its size, solar orientation and the time of day the measurement is taken. However, different glazing types possess unique solar heat gain characteristics.

Advances in glazing and coating technologies have resulted in products that can selectively transmit or reflect certain wavelengths of light. A spectrally selective glazing unit possesses optical properties that behave differently in one part of the spectrum than in others. Therefore, glazings can be chosen to either transmit or reject solar heat.



Figure 2. The solar spectrum. 


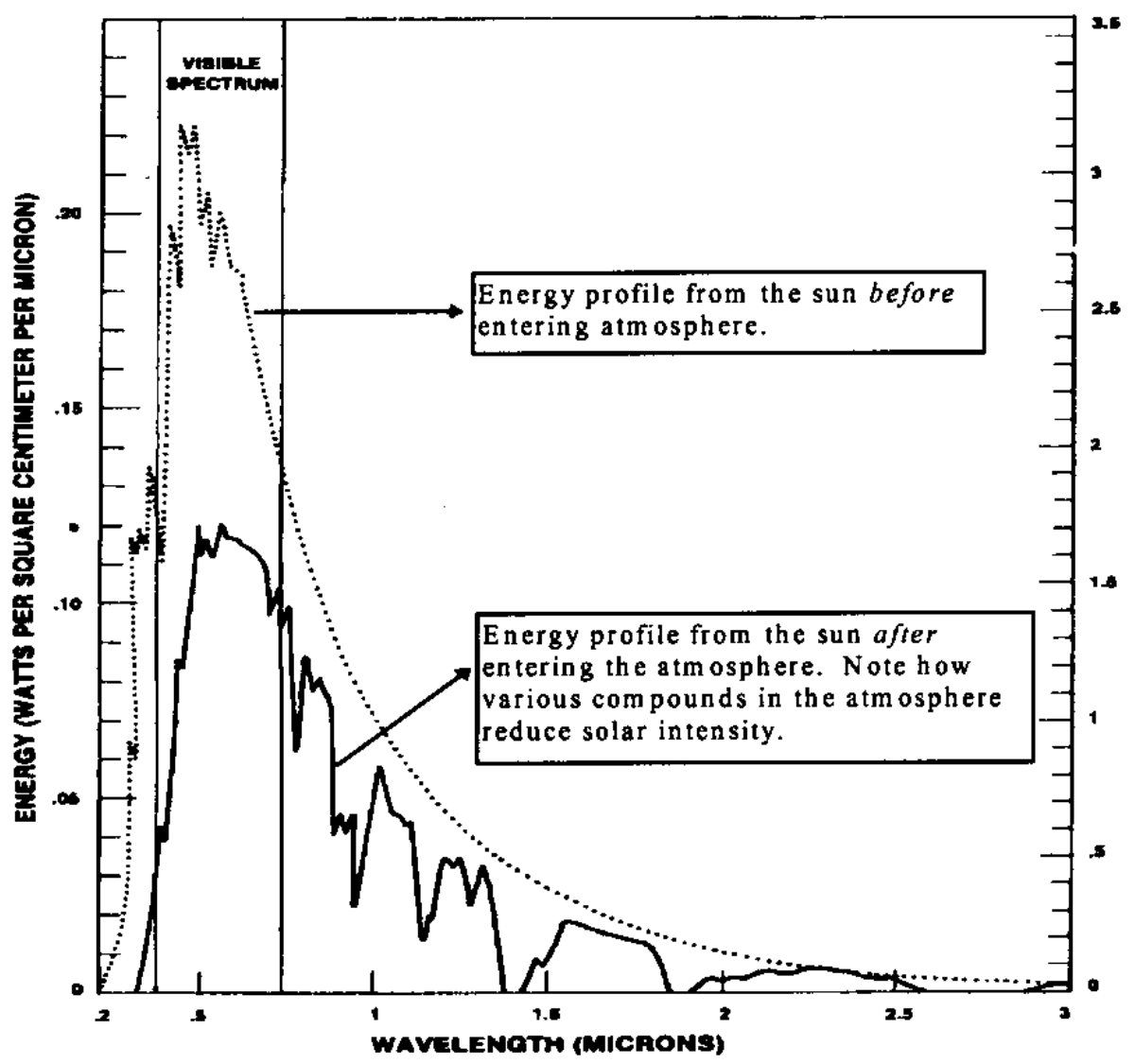

Figure 3. Energy intesity and wavelength.

Almost all architectural glass blocks long-wave radiation (far infrared) emitted by surfaces at temperatures below about $250{ }^{\circ} \mathrm{F}$. This characteristic is instrumental in producing the greenhouse effect. The greenhouse effect is caused by exterior visible and near infrared light that is transmitted through a glazed surface and is absorbed by interior surfaces. This energy heats up the interior objects and is re-emitted at a much longer wavelength. The longer wavelength energy cannot escape the interior by transmission through the glass, because, as mentioned, glass blocks long-wave radiation. This long-wave radiation is then absorbed by the glass and re-emitted to both sides of the glass surface, reheating the objects within the space and effectively "trapping" large portions of the energy inside.

As noted previously, the three main radiative properties of glass are transmittance, reflectance, and absorptance. Together they describe what can happen to radiative energy when it is incident to, or falls upon, a pane of glass. The radiative energy is transmitted through the glass, reflected by the glass, or absorbed by the glass. Values that are typically assigned to the three properties range between 0.0 and 1.0 and reflect the percentage of incident radiant energy 
that is transmitted, absorbed, and reflected. For example, if we consider a sheet of clear glass and combine all of the possible wavelengths and directions of incoming sunlight, the solar properties are roughly as follows: transmittance (0.86), reflectance (0.08), and absorptance $=(0.06)$. Note that these three properties must add up to 1.0 to account for all the radiant energy.

If 86 percent of the available solar energy is transmitted, the transmittance is said to be equal to 0.86 (Figure 4). If 6 percent is absorbed, the absorptance is 0.06 . Likewise, if 8 percent is reflected, the reflectance is equal to 0.08 . At any time, the sum of these radiative properties must equal 1 .

The properties can vary considerably depending on glass thickness, number of panes of glass, amount of impurities, texture, and any coatings or tints that have been added. The properties will also depend on the wavelength and direction of the incoming light. It is important to be aware of the spectral (wavel ength) aspects of radiative properties, because many coatings and tints alter these properties to enhance or suppress the transmission of radiant energy through the glazing.

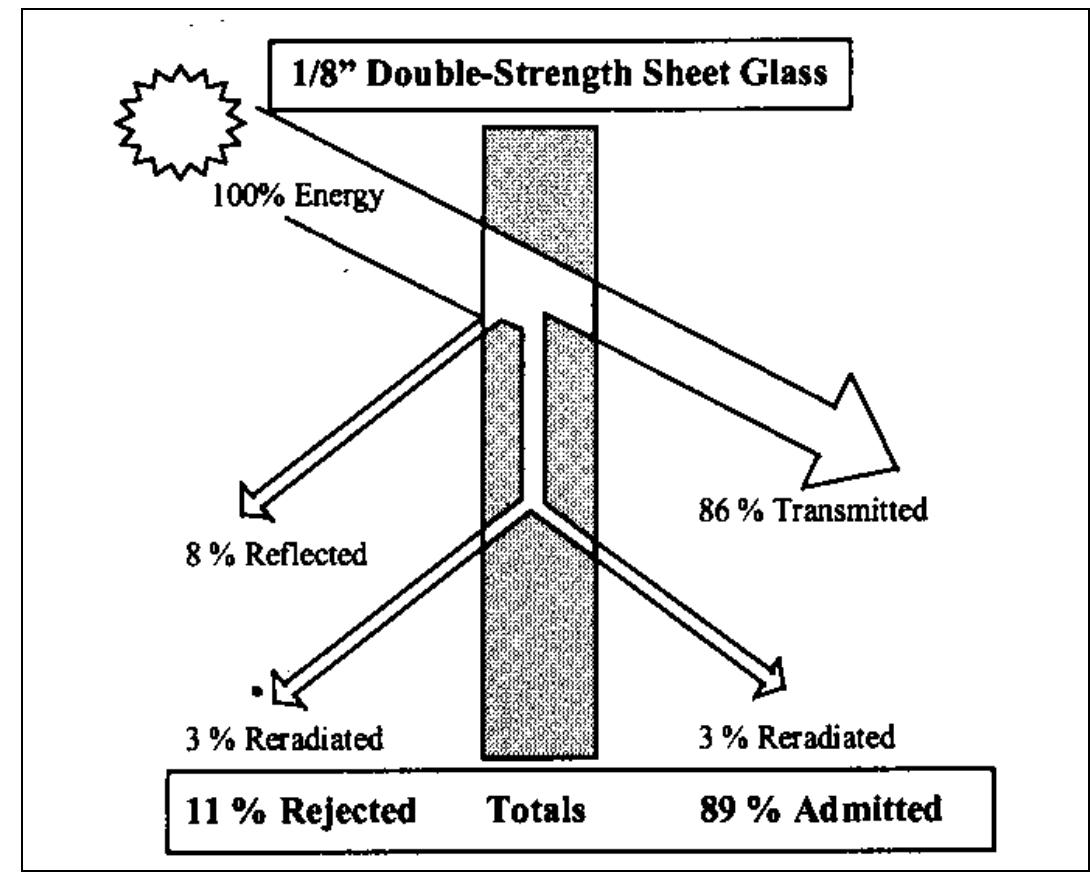

Figure 4. Effects of light on glass. 


\section{Glazing Thermal Performance}

\section{Performance Indicators}

R-value, shading coefficient, coolness index, and solar heat gain coefficient are performance indicators that must be considered to effectively evaluate heat transfer behavior. In cold weather conditions it is desirable to suppress conductive, convective, and radiative heat transfer from the high-energy indoors to the low-energy outdoors. However, it is also desirable to enhance the solar radiative heat transfer from the outdoors (sun) to the indoors. Therefore, when considering a glazing performance indicator, it is important to know what modes of heat transfer are being measured by that indicator. Because glazing systems can differ greatly and their surrounding thermal environments are constantly changing, performance indicators do not remain constant and might vary slightly in an actual application.

If we disregard solar radiation, air leakage, and moisture condensation, the rate of heat transfer through a glazing system is proportional to the difference in air temperature between the outdoors and the indoors as expressed by the equation

$$
\mathrm{Q}=\mathrm{UA}(\Delta \mathrm{T})
$$

where

$$
\begin{aligned}
& \mathrm{Q}=\text { total rate of heat transfer }(\mathrm{Btu} / \mathrm{hr}) \\
& \mathrm{U}=\text { overall heat transfer coefficient, or } \mathbf{U} \text {-value }\left(\mathrm{Btu} /\left(\mathrm{hr} \mathrm{ft}^{2}{ }^{\circ} \mathrm{F}\right)\right. \\
& \mathrm{A}=\text { area of the glazing system }\left(\mathrm{ft}^{2}\right) \\
& -\mathrm{T}=\text { indoor-outdoor temperature difference }\left({ }^{\circ} \mathrm{F}\right)
\end{aligned}
$$

The $U$-value is a measure of that system's ability to transfer energy under the above assumptions. It is the rate of energy (Btu) flowing through a $1 \mathrm{ft}^{2}$ piece of material or assembly with a $1^{\circ} \mathrm{F}$ difference in temperature between sides for 1 hr. U-value can be thought of as a "nonsolar" performance indicator that combines the effects of conduction, convection, and thermal radiation caused by the indoor-outdoor temperature difference.

It should be noted that $U$-values do not take into account the ability to transmit solar radiation. For comparison purposes and for code compliance, U-values are 
measured under standardized thermal conditions, because the actual U-value for a glazing system will change as conditions around it change. A designer may sometimes encounter a "summer" $U$-value (when heat flow is primarily from outside toward the inside) and a "winter" U-value (when heat flow is primarily from inside toward the outside).

Also, different regions of a glazing system will have different U-values. Reported U-values are sometimes a combination of the U-values measured at the center-of-glass, edge-of-glass, and the frame. Sometimes only the center-ofglass $\mathrm{U}$-value is offered. Care must be taken when comparing $\mathrm{U}$-values to ensure that they were calculated in a consistent manner. The most accurate information is the measure of the total window system. Good sources of Uvalues for windows are the American Society of Heating, Refrigerating, and AirConditioning Engineers' (ASHRAE 1993) "Handbook of Fundamentals" (Chapter 27, Table 5) and the National Fenestration Rating Council's "Certified Products Directory."

Another thermal performance indicator is the R-value. The R-value is the inverse of the $\mathrm{U}$-value and is thus a measure of the system's ability to resist heat transfer*

Table 1 describes the physical and optical properties for 14 glazing configurations. Glazing configuration No. 2 (a single pane of 1/8-in. clear glass) is used as the baseline (1.0) for calculating shading coefficients. All values shown are for center-of-glass measurements. Other factors, such as dividers and window frame type, material, and size, can affect a system's performance. Therefore, the values shown in Table 1 are for the glazing only.

The shading coefficient $\left(\mathrm{SC}_{\mathrm{c}}\right)$ is an indicator of how well a glazing transmits solar energy. It can be thought of as the "solar" performance indicator. The SC is the ratio of solar energy transmission through a specific glazing relative to that of a clear, double-strength, 1/8-in.-thick single-pane glass. The $\mathrm{SC}_{\mathrm{c}}$ is a number between 0 and 1 , with high $\mathrm{SC}_{c}$ values indicative of a glazing type that transmits almost as much as clear glass, ideal for winter or for high solar heat gains. Lower $\mathrm{SC}_{c}$ values indicate that the glazing will block a portion of the incident solar energy, ideal for the summer or for reduced cooling loads. SCc

* Sources of information on energy-efficient window design are listed in Appendix A. 
values alone do not determine the amount of solar energy that will pass through a surface; glazing size, orientation, and shading devices are also factors.

The solar heat gain coefficient $\left(\mathrm{SHGF}_{c}\right)$ is a measure of the rate of solar heat flowing through a window or skylight. Solar heat gain coefficients allow consumers to compare the solar heat gain properties of different windows and skylights. The solar heat gain coefficient accounts for the transmissive glazing element, as well as the opaque frame and sash.

$\mathrm{T}_{\text {sol }}$ is the solar transmittance of the glazing system, with a value of 1.0 indicating full transmission and zero indicating an opaque surface. This is a measure of the solar transmittance across the entire solar spectrum, including UV, visible, and infrared energy.

Table 1. Physical and optical properties of sample configurations

\begin{tabular}{|c|c|c|c|c|c|c|c|c|}
\hline \multirow{2}{*}{\multicolumn{2}{|c|}{$\begin{array}{l}\text { Glazing type and } \\
\text { thickness (in.) }\end{array}$}} & \multicolumn{7}{|c|}{ Shading Coefficient } \\
\hline & & $S C_{c}$ & SHGF & $T_{s o l}$ & $T_{v i s}$ & $K_{e}$ & $\boldsymbol{U}_{c}$ & $\boldsymbol{R}_{c}$ \\
\hline 1 & Single Pane - 3/32 & 1.01 & 0.87 & 0.850 & 0.90 & 0.891 & 1.11 & 0.901 \\
\hline 2 & Single Pane - 1/8 & 1.0 & 0.86 & 0.837 & 0.90 & 0.900 & 1.11 & 0.901 \\
\hline 3 & Single Pane - $1 / 4$ & 0.95 & 0.82 & 0.775 & 0.88 & 0.926 & 1.09 & 0.917 \\
\hline 4 & Single Pane - $1 / 2$ & 0.84 & 0.73 & 0.653 & 0.84 & 1.000 & 1.04 & 0.962 \\
\hline 5 & Double Pane - 3/32 & 0.90 & 0.78 & 0.727 & 0.82 & 0.911 & 0.49 & 2.041 \\
\hline 6 & Double Pane - 1/8 & 0.89 & 0.76 & 0.705 & 0.81 & 0.910 & 0.49 & 2.041 \\
\hline 7 & Double Pane - $1 / 4$ & 0.81 & 0.70 & 0.604 & 0.78 & 0.963 & 0.48 & 2.083 \\
\hline 8 & Double Pane - 1/2 & 0.67 & 0.58 & 0.428 & 0.71 & 1.060 & 0.46 & 2.174 \\
\hline 9 & DBL Low-emissivity & 0.69 & 0.60 & 0.544 & 0.77 & 1.116 & 0.32 & 3.125 \\
\hline 10 & DBL Low-emissivity w/Argon & 0.69 & 0.60 & 0.544 & 0.77 & 1.116 & 0.27 & 3.704 \\
\hline 11 & Triple Pane - 3/32 & 0.81 & 0.70 & 0.624 & 0.74 & 0.914 & 0.32 & 3.125 \\
\hline 12 & Triple Pane - 1/8 & 0.79 & 0.68 & 0.595 & 0.74 & 0.937 & 0.32 & 3.125 \\
\hline 13 & 3/32 + HM88 + 3/32 & 0.67 & 0.58 & 0.488 & 0.73 & 1.090 & 0.23 & 4.348 \\
\hline 14 & $3 / 32+\mathrm{HM} 22+3 / 32$ & 0.16 & 0.14 & 0.088 & 0.70 & 4.375 & 0.21 & 4.762 \\
\hline \multicolumn{9}{|c|}{ 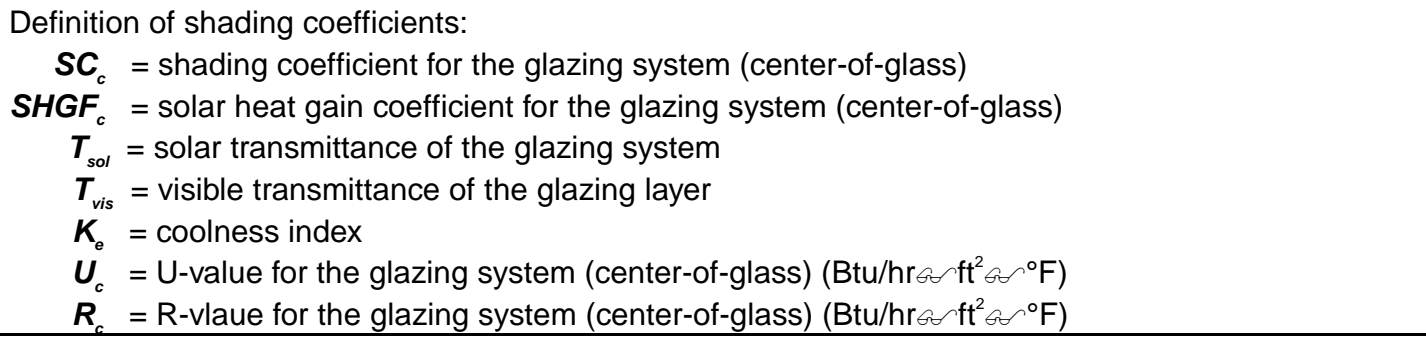 } \\
\hline
\end{tabular}


Visible transmittance $\left(T_{\text {vis }}\right)$ is the ability of the glazing to transmit daylight, or radiation in wavelengths visible to the human eye. The visible transmittance is an important factor in determining daylight penetration. The visible transmittance can be very different from solar transmittance in two panes that appear identical.

The coolness index or $\left(\mathrm{K}_{\mathrm{e}}\right)$ is the ratio of visible transmittance to shading coefficient. It is represented in the formula $\mathrm{K}_{\mathrm{e}}=\left(\mathrm{T}_{\mathrm{vis}} / \mathrm{SC}_{\mathrm{c}}\right)$.

Excluding far-infrared, clear glass is evenly transmissive throughout the solar spectrum. The $\mathrm{K}_{\mathrm{e}}$ of clear glass is given a value of 1.0. Tints that lower the visible transmittance but maintain the transmittance of infrared (or solar heat gain) have a $\mathrm{K}_{\mathrm{e}}$ less than 1.0. Low emissivity (low-e), selective tints, and other products that have a lower shading coefficient and more visible light have a $\mathrm{K}_{\mathrm{e}}$ greater than 1.0. A superior, spectrally selective glass will have a $K_{e}>1.0$, while inferior glass will have a $\mathrm{K}_{\mathrm{e}}<1.0$.

Additional glazing layers provide more barriers to solar radiation, thus reducing the solar heat gain coefficient of a window. Tinted glazings, such as bronze and green, provide lower solar heat gain coefficients than clear glass. Low-e coatings can be engineered to reduce window solar heat gain coefficients by rejecting more of the incident solar radiation. Spectrally selective glazings block out much of the sun's heat while maintaining a higher visible transmittance and more neutral colors than more heavily tinted bronze and gray glazings. Hightransmittance, low-e coatings, used in conjunction with a tinted outer glass layer, also reduce solar heat gain by preventing the absorbed heat from reaching the interior space. Mirror-like reflective glazings are commonly used in office buildings, but are rarely chosen for residences. While reflective glazings may have very low solar heat gain coefficients, they block so much of the light and view that they are not normally desirable in homes.

Additional reference sources on energy efficient design of windows and glazing are listed in Appendix B.

Table 2 shows representative solar heat gain coefficients and visible transmittances for glazings with typical wood or vinyl frames and aluminum spacers. Aluminum-frame windows of comparable size and glazing type generally have slightly higher solar heat gain coefficients because of their thinner frames and greater glazing areas. It should also be noted that the total window visible transmittance can be considerably less than the glazing visible transmittance due to frame and divider shading effects. Table 2 also illustrates 
that it is possible to have windows with high visible transmittance while having a relatively low solar heat gain coefficient.

Table 2. Representative window solar heat gain coefficients and visible transmittances*

\begin{tabular}{|c|c|c|c|}
\hline Glazing type and thickness (in.) & $\begin{array}{c}\text { Solar heat gain coefficient } \\
\left(S H G F_{c}\right)\end{array}$ & $\begin{array}{l}\text { Total windown visible } \\
\text { transmittance }\left(T_{\text {vis }}\right)\end{array}$ & $\begin{array}{l}\text { Glazing visible } \\
\text { transmittance }\end{array}$ \\
\hline Single glass, clear & 0.63 & 0.66 & 0.90 \\
\hline Single glass, bronze tint & 0.55 & 0.50 & 0.69 \\
\hline Single glass, green tint & 0.55 & 0.60 & 0.82 \\
\hline $\begin{array}{l}\text { Single glass, clear with solar } \\
\text { control film }\end{array}$ & 0.33 & 0.18 & 0.25 \\
\hline $\begin{array}{l}\text { Double glass, clear, } 1 / 2 \text {-in. air } \\
\text { space }\end{array}$ & 0.59 & 0.60 & 0.82 \\
\hline $\begin{array}{l}\text { Double glass, bronze tint outer } \\
\text { pane, } 1 / 2 \text {-in air space }\end{array}$ & 0.48 & 0.45 & 0.62 \\
\hline $\begin{array}{l}\text { Double glass, green tint oputer } \\
\text { pane, } 1 / 2 \text {-in. air space }\end{array}$ & 0.48 & 0.54 & 0.74 \\
\hline $\begin{array}{l}\text { Double glass, clear }(e=0.15)^{\star *} \text {, } \\
1 / 2 \text {-in. air space }\end{array}$ & 0.50 & 0.55 & 0.76 \\
\hline $\begin{array}{l}\text { Double glass, "Southern" low-e } \\
(e=0.08) \text {, on tint } 1 / 2-\text { in. argon } \\
\text { space }\end{array}$ & 0.27 & 0.32 & 0.44 \\
\hline $\begin{array}{l}\text { Double glass, spectrally } \\
\text { selective }(e=0.04), 1 / 2 \text {-in. argon } \\
\text { space }\end{array}$ & 0.34 & 0.52 & 0.71 \\
\hline $\begin{array}{l}\text { Triple glass, clear }(\mathrm{e}=0.15 \text { on } \\
\text { two panes), } 3 / 8 \text { to } 1 / 2 \text { in. air or } \\
\text { argon space }\end{array}$ & 0.41 & 0.47 & 0.65 \\
\hline \multicolumn{4}{|c|}{$\begin{array}{l}\text { Source: WINDOW } 4.1 \text { (1994) (See Appendix A) } \\
{ }^{*} \text { Results from WINDOW } 4.1 \text { are for } 3 \text {-foot-by-5-foot windows with wood or vinyl frames and aluminum } \\
\text { spacers. Solar heat gain coefficients vary somewhat with window size. } \\
{ }^{* *} \text { Emittance of the low-e coatind surface; will vary slightly with specific products. }\end{array}$} \\
\hline
\end{tabular}

Figure 5 describes the surface numbers (nomenclature) that relate to the description of glazing assemblies that follows. Table 3 shows the temperature profiles for the outside surface (1), center-of-glass (a) and inside surface (2) temperatures for various glazing configurations. Glazing systems 1 through 4 are clear, single-pane glass of varying thickness. Glazing types 5 through 10 are double-pane configurations. For example, No. 5 is two panes of 3/32-in. clear glass with a $1 / 2$-in. air space between. Number 9 has an outer pane of 1/8-in. glass that has a low-e coating on the inside surface of the outer pane. Number 10 is the same configuration as No. 9 except that the air between the panes has been replaced with argon gas. Numbers 11 through 14 are triple-pane configurations. All temperatures are for center of glass. 


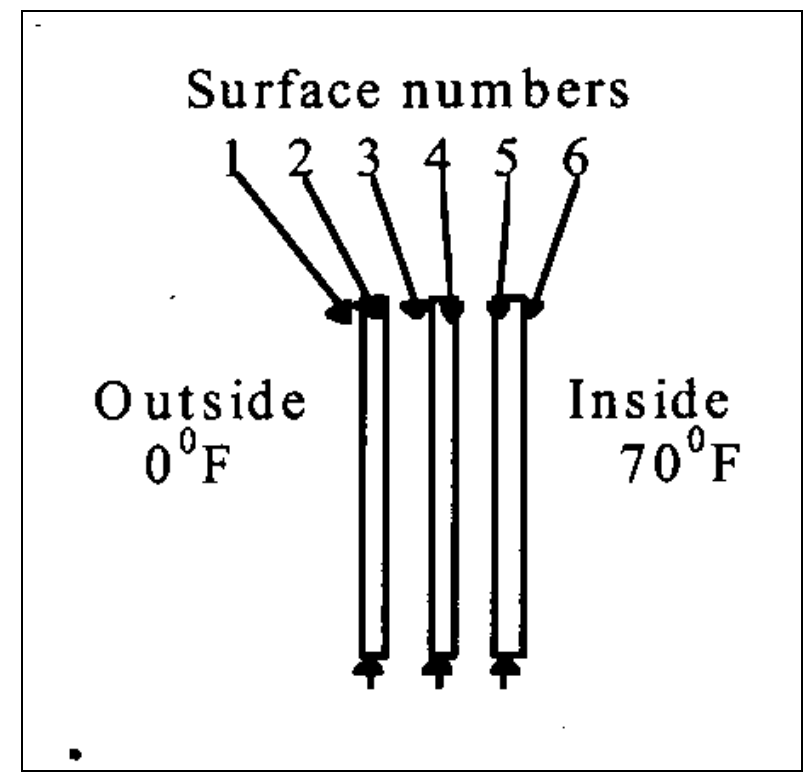

Figure 5. Glass pane nomenclature.

Table 3. Temperature profiles $\left({ }^{\circ} \mathrm{F}\right)$ and relative humidity (\%)

\begin{tabular}{|c|c|c|c|c|c|c|c|c|c|c|c|}
\hline & \multirow{3}{*}{$\begin{array}{l}\text { Glazing type and } \\
\text { thickness (in.) }\end{array}$} & \multicolumn{10}{|c|}{ Temperature profile $\left({ }^{\circ} \mathrm{F}\right)^{\star}$} \\
\hline & & \multirow{2}{*}{$\begin{array}{c}1 \\
O S \\
\end{array}$} & \multirow{2}{*}{$\begin{array}{l}a \\
C\end{array}$} & \multirow{2}{*}{$\begin{array}{l}2 \\
I S \\
\end{array}$} & \multirow{2}{*}{$\begin{array}{c}3 \\
\text { OS }\end{array}$} & \multirow{2}{*}{$\begin{array}{l}b \\
c \\
\end{array}$} & \multirow{2}{*}{$\begin{array}{l}4 \\
I S \\
\end{array}$} & \multirow{2}{*}{$\begin{array}{c}5 \\
O S \\
\end{array}$} & \multirow{2}{*}{$\begin{array}{l}\mathrm{C} \\
C \\
\end{array}$} & \multirow{2}{*}{$\begin{array}{l}6 \\
I S \\
\end{array}$} & \multirow[b]{2}{*}{$\mathbf{R H}(\%)$} \\
\hline & & & & & & & & & & & \\
\hline 1 & Single Pane - 3/32 & 15.4 & 16.0 & 16.6 & & & & & & & 12.8 \\
\hline 2 & Single Pane - 1/8 & 15.3 & 16.8 & 16.8 & & & & & & & 12.9 \\
\hline 3 & Single Pane - 1/4 & 15.0 & 17.9 & 17.9 & & & & & & & 13.5 \\
\hline 4 & Single Pane - $1 / 2$ & 14.4 & 19.9 & 19.9 & & & & & & & 14.8 \\
\hline 5 & Double Pane - 3/32 & 6.8 & 7.4 & 7.4 & 44.8 & 45.0 & 45.3 & & & & 41.1 \\
\hline 6 & Double Pane - 1/8 & 6.8 & 7.5 & 7.5 & 44.7 & 45.0 & 45.4 & & & & 41.2 \\
\hline 7 & Double Pane - 1/4 & 6.7 & 8.0 & 8.0 & 44.5 & 45.2 & 45.8 & & & & 41.9 \\
\hline 8 & Double Pane - 1/2 & 6.4 & 8.9 & 8.9 & 44.2 & 45.4 & 46.6 & & & & 43.2 \\
\hline 9 & Dbl low-e & 4.4 & 4.8 & 4.8 & 53.2 & 53.4 & 53.6 & & & & 55.9 \\
\hline 10 & Dbl low-e with argon & 3.7 & 4.1 & 4.1 & 55.8 & 56.0 & 56.1 & & & & 61.4 \\
\hline 11 & Triple Pane - 3/32 & 4.4 & 4.7 & 4.7 & 30.1 & 30.3 & 30.5 & 53.3 & 53.5 & 53.7 & 56.1 \\
\hline 12 & Triple Pane 1/8 & 4.4 & 4.8 & 4.8 & 30.1 & 30.3 & 30.5 & 53.3 & 53.5 & 53.7 & 56.2 \\
\hline 13 & $3 / 32+\mathrm{HM} 88+3 / 32$ & 3.2 & 3.4 & 3.4 & 40.3 & 40.2 & 40.3 & 57.7 & 57.8 & 57.9 & 65.5 \\
\hline 14 & $3 / 32+\mathrm{HM} 22+3 / 32$ & 2.9 & 3.2 & 3.2 & 42.7 & 42.7 & 42.8 & 58.6 & 58.7 & 58.9 & 67.7 \\
\hline $\begin{array}{l}\text { Def } \\
\text { OS } \\
\mathrm{C} \\
\text { IS } \\
\mathrm{RH} \\
{ }^{*} \mathrm{Re}\end{array}$ & $\begin{array}{l}\text { initions: } \\
=\text { outside surface temp } \\
=\text { center-of-glass tempe } \\
=\text { inside surface temper } \\
=\text { relative humidity at wl } \\
\text { efer to Figure } 5 \text { for a des }\end{array}$ & $\begin{array}{l}\text { rature } \\
\text { ature } \\
\text { ture } \\
\text { ch con } \\
\text { ription }\end{array}$ & $\begin{array}{l}\text { glass } \\
\text { glio }\end{array}$ & $\begin{array}{l}\text { will oc } \\
\text { ane no }\end{array}$ & ur & re $(1-6$ & and a-c & & & & \\
\hline & urce: WINDOW 4.1 (199 & (see & opend & & & & & & & & \\
\hline
\end{tabular}


The column labeled RH (relative humidity) is the indoor relative humidity at which condensation would occur on the inside surface of the glass. It is interesting to note the vast difference between the high and low values. Also note the significant difference that occurs simply by replacing air with argon (No. 9 versus No. 10).

The comfort implications of the various glazing configurations are clearly illustrated by observing the innermost surface temperature. A human body will radiate far more energy toward a surface that is in the high teens $\left(17-19{ }^{\circ} \mathrm{F}\right)$ than it will toward a surface that is in the range of 45 to $58^{\circ} \mathrm{F}$. The single-pane glazing will appear as a very cold surface compared with the other configurations. Colder surfaces can also contribute significantly to the creation of drafts and uncomfortably cold air currents.

Configuration types 13 and 14 (Table 3) replace the center pane of glass in a triple-pane configuration with a special heat-rejecting film. Different types of low-emissivity, wavelength-selective films are available. The difference between the films is their ability to reflect infrared energy. It is interesting to note how effective these films are in reflecting heat back to the interior, and conversely, blocking infrared energy during the summer.

Standard conditions (outside air $=0{ }^{\circ} \mathrm{F}$; inside air $=70^{\circ} \mathrm{F}$ ) were used for all the analyses. All air spaces were $1 / 2$ in. wide.

\section{Center Glass versus Whole Unit}

When determining the energy performance of glazed surfaces, it is important to note the entire assembly of the window unit. Prior to 1989, the ASHRAE method for determining overall window R-value was based on estimating the losses associated with the particular glazing type (typically calculated at the center of the glass component). A correctional factor was then applied for the frame R-value. Frames were assumed to slightly improve the overall R-value of the window assembly.

Recent technological improvements in glazing thermal performance have created the opposite condition. Glazing is now typically the most thermally efficient component of the window system, with edges and frames reducing the overall R-value. The new calculation method has, in some cases, reduced reported R-values from 1989 levels. 


\section{Ultraviolet Protection}

Ultraviolet radiation is the main component of sunlight that can fade and damage drapes, carpets, furniture, and paintings when transmitted through windows and skylights. Efforts to produce window glazings that transmit less ultraviolet energy have met with some success. In general, windows and skylights with plastic glazing layers or low-e coatings reduce UV transmission. However, even without any UV radiation, sunlight can still cause fading of fabrics and other furnishings.

Clear glass transmits approximately 70 percent of the UV radiation. It is possible to remove most, but not all, of the UV light. Plastics inherently block more UV than glass, reducing the transmission to a total of 0.05 percent for units that use suspended films (see Chapter 4, Low-e and Reflective Coatings). It should be noted that some UV is visible and cannot be blocked without reducing the visible light. Glass with high visible transmittance $\left(T_{\text {vis }}\right)$ will transmit more UV, than glass with a lower $T_{\text {vis. }}$.

\section{Condensation Prevention}

Air can hold varying amounts of water vapor or moisture. The warmer the air is, the more moisture it can hold. The amount of moisture in the air, expressed as a percentage of the maximum amount the air could hold at a given temperature, is called its relative humidity. For health and comfort, indoor air should contain some moisture. The relative humidity should generally be between 30 percent and 40 percent at normal room temperature.

The relative humidity of air can be increased by adding more moisture or by reducing the temperature. When the relative humidity reaches 100 percent, the air can hold no more moisture and water begins to condense from it. The temperature at which this condensation occurs is called the dew point temperature of the air. When moist air comes in contact with a cold surface in a home, it may be cooled to its dew point temperature, resulting in condensation on the surface.

Windows do not cause condensation. Typically, however, windows are the first and most obvious place that condensation in a building occurs. This is because windows generally have a lower thermal resistance than insulated walls, ceilings, and floors. As a result, their inside temperatures are usually lower than those of other surfaces in a home during cold weather. If the air in a home 
is humid enough, water will condense from it when it is cooled at a window surface. Condensation is most often thought of as a cold-climate, winter problem. However, in hot humid weather, moisture can condense on the outside surface of a poorly insulated window in an air-conditioned building.

Left unchecked, condensation can damage window frames, sills, and interior shades. Water can deteriorate the surrounding paint, wallpaper, plasterboard, and furnishings. In severe cases, it can seep into adjoining walls, causing damage to the insulation and framing.

The indoor air coming into contact with energy-efficient windows is less likely to be cooled to its dew point temperature because the inside surface temperatures remain higher during cold weather than do those of windows with single glazing, traditional metal spacers, and metal frames.

Figure 6 illustrates conditions under which condensation will form on the center of the glass of three glazing types with widely varied U-factors. The graph shows clearly that the risk of condensation at the center of the glass is reduced as the insulating value of the glass increases. Even at an outdoor air temperature of $-30{ }^{\circ} \mathrm{F}$, the indoor air relative humidity must be nearly 50 percent before condensation will form on the triple glazing with two low-e coatings. On the other hand, at an outdoor temperature of $10^{\circ} \mathrm{F}$, condensation will form on the single glazing at an indoor relative humidity of only 18 percent.

Figure 6 shows outdoor air temperature and indoor air $\mathrm{RH}$ combinations at which condensation will occur on the center of the glass for single glazing, double glazing, and triple glazing with two low-e $(e=0.15)$ coatings. On or above each curve, the conditions are right for condensation. Below each curve, condensation will not occur on that glazing type as long as the glazing is exposed to room air circulation. Results are based on winter conditions: $70{ }^{\circ} \mathrm{F}$ indoor air temperature, $15 \mathrm{mph}$ outdoor air velocity, and no incident solar radiation.

Condensation is even more likely to occur at window spacers and frames, which are usually less insulative than the corresponding glazings. With so many insulating glazing types available, efforts to prevent condensation have shifted toward the development of better insulating spacers and frames. 


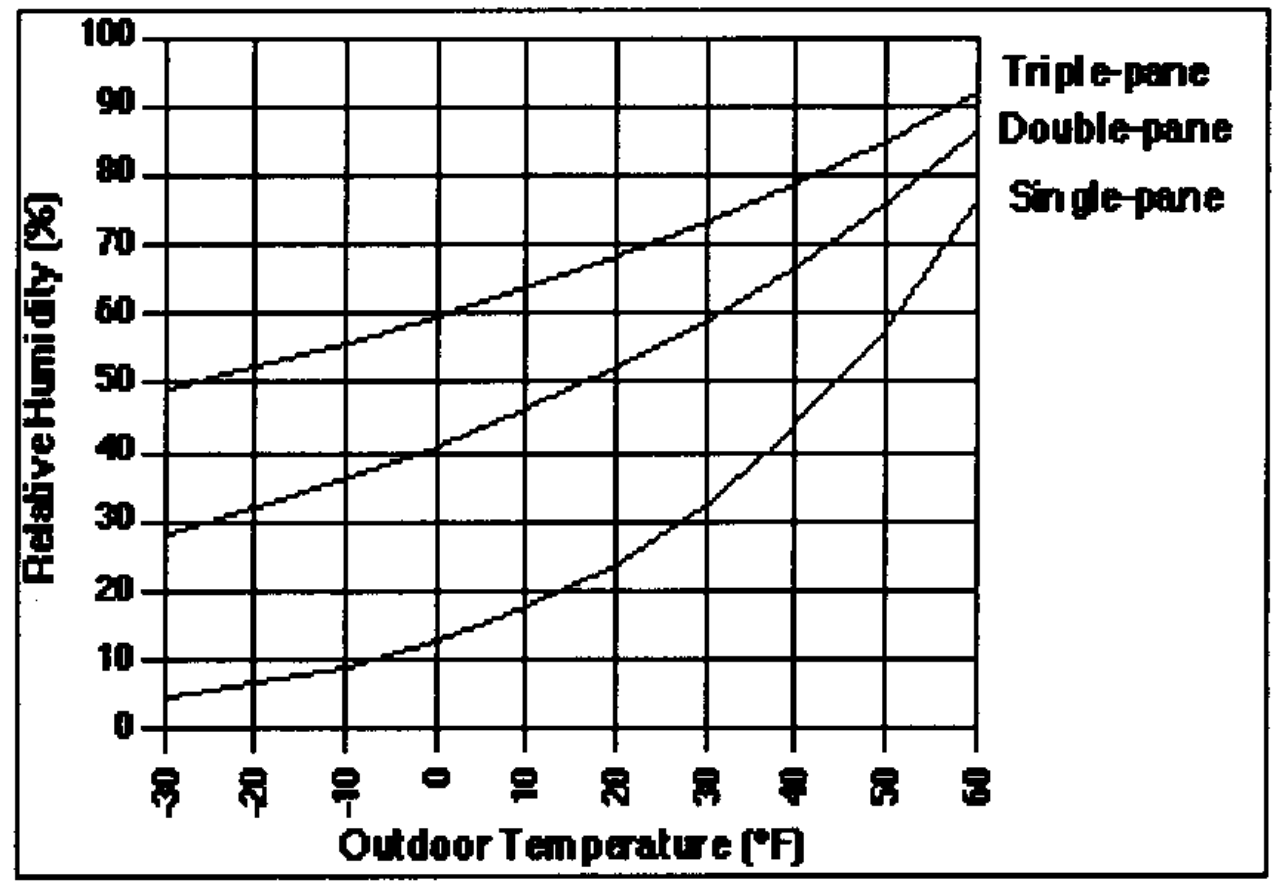

Figure 6. Conditions for window condensation. 


\section{Glazing Technologies}

This chapter provides information on some of the glazing system options currently available and new technologies being developed. Many of these systems can be combined to increase the performance of the overall unit.

\section{Glass and Tints}

Clear float glass is the typical type of glass used today. It is manufactured by placing molten glass on a tin bath. Because the glass is lighter than tin, it floats, creating a clear, completely smooth surface with two parallel sides. Clear glass has no significant thermal resistance (R-value) from the pane itself. However, it has a value of R-0.9 to R-1 due to the thin films of air on the interior and exterior surfaces of the glass. It also has a high ability to transmit visible and near-infrared light.

Tints are absorptive materials that are available in both glass and plastic glazings. Tints are typically added to the material while in the molten stage of manufacturing and are dispersed within the glass mixture. They can be used in a single or multiple pane system. Tints absorb a portion of the incident solar radiation. The absorbed radiation is then transformed into heat within the glass, and depending upon the interior and exterior climatic conditions, some of this unwanted heat may be transferred to the building interior. Absorptance levels depend on the absorbing material (tint) and the thickness of the glass. Thicker glass provides more absorptance and transmits less visible light.

The application of tints lowers the shading coefficient of clear glass because some of the light and solar heat is reflected and absorbed. Common tints available are gray, bronze, blue, green, and combinations of these shades. Characteristics of these tints are summarized below.

- Gray glass transmits approximately equal amounts of visible light and infrared.

- Bronze glass transmits less visible light and more infrared than gray glass. 
- Blue and green glass transmit more visible light and less infrared than gray glass.

Tinted glass alone can only reduce a shading coefficient to about 0.65 . Combining tints with other glazing technologies such as reflective surfaces and coatings can further reduce shading coefficients $\left(\mathrm{SC}_{\mathrm{c}}\right)$ or improve the coolness index $\left(\mathrm{K}_{\mathrm{e}}\right)$. To be most effective (reduce interior heat gain), the tinted glass pane should be used as the exterior pane of a double-pane or insulated glass system.

Mirrored glazing is a form of tinted glazing consisting of metallic particles that reflect visible radiation. The $\mathrm{SC}_{c}$ and the solar heat gain coefficient $\left(\mathrm{SHGC}_{c}\right)$ of this type of glazing should be evaluated carefully before specification. It can reduce the indoor natural light considerably, creating dark, unpleasant interior spaces. Heat Mirror glass has also been reported to increase the $\mathrm{SHGC}_{c}$ on adjacent buildings from reflected solar radiation.

Translucent coatings allow for the transmission of most of the visible light, but disperse or scatter the light and distort the view. Translucent coatings can be placed within the glass, embossed on the surface, or applied as a surface film. They are useful for applications where indirect daylight and privacy are desired. Translucent glass alone may have little, if any, effect on the $\mathrm{SC}_{c}$ or $\mathrm{T}_{\text {vis }}$ of the glass. As with tinted glass, it can be added to a system to enhance properties or meet specific needs.

Spectrally selective tints are created to be naturally selective to visible light. These tints are more selective in the visible and near-infrared spectrum than traditional tints and maintain relatively low $\mathrm{SC}_{c}$ and high $\mathrm{T}_{\text {vis. }}$. The addition of selective coatings (low-e) can increase the $K_{e}$, whereas reflective coatings can decrease the $\mathrm{K}_{\mathrm{e}}$. Coatings on suspended films between glass offer even more flexibility in $\mathrm{K}_{\mathrm{e}}$ targets.

\section{Low-E and Reflective Coatings}

Low-emissivity coatings were developed in the early 1970s primarily by the Massachusetts Institute of Technology (MIT) and introduced into the market around 1980. Most low-e coatings have relatively high $\mathrm{T}_{\text {vis }}$ and reflect 40 to 70 percent of infrared. Put loosely, low-e lets in light but blocks the heat. Various low-e coatings allow different amounts of UV radiation, ranging from a 0.05 - to 37-percent reduction. 
A low-e coating is a microscopically thin, virtually invisible, metal or metallic oxide coating deposited on a glazed surface. The coating may be applied to one or more of the glazing surfaces facing an air space in a multiple-pane window, or to a thin plastic film inserted between panes. The coating limits radiative heat exchange between panes by reflecting heat back into the home during cold weather and back to the outdoors during warm weather. This effect increases the insulating value of the window. A low-e coating can be applied on glass or plastic films using one of two methods.

1. Pyrolytic (hard coat) is a single layer of metallic oxides applied while the glass is still in a semimolten state. This surface is strong and durable and can be used on single-pane units. It has the highest shading coefficient $\left(\mathrm{SC}_{\mathrm{c}}\right)$ of low-e coatings (compared to sputtered) and can sustain high temperatures (i.e. can be used in solar collectors). The drawback of this surfacing is that it may make large expanses of glass look slightly blotchy with color shifts away from truly "clear."

2. Sputtered (soft coat) is a multilayer application of a metallic, heat-reflecting layer sandwiched between two antireflective dielectric coatings to maintain light transparency. The layers are applied to finished glass in a vacuum chamber. This system is fragile and must be protected in an multipane unit. It has the lowest $\mathrm{SC}_{\mathrm{c}}$ of the low-e coatings. Sputtered coatings are currently the most common application, roughly 80 percent of the market.

Various methods are used to integrate the low-e coated surfaces into window assemblies

- Low-e coated glazing is used on one of the panes in an multipane unit. The low-e coating can either be located on the inside of the exterior pane or on the exterior of the interior pane, depending on desired performance.

- Suspended coated film (SCF) is a low-e system developed to insulate better than typical low-e and provide more flexibility in $K_{e}$ values. Using the sputtering process, a wavelength-selective low-e coating is applied to thin plastic film that is then suspended between two plates of glass. This creates a unit that, as far as convection and conduction are concerned, is essentially a triple-pane unit. The two airspaces also provide better sound control than standard multipane units. What differentiates SCF units is the spectrally selective coating on the suspended film. The coating blocks over 99 percent of UV radiation without blocking significant portions of visible light. The result is a unit with a low shading coefficient and high visible light 
transmission. Several coating types are available so that the appropriate shading coefficient and amount of light transmission and insulating value can be selected for a given application. Combining different glazing options is an excellent way to achieve desired performance. For example, the combination of two suspended films, low-e glass, and inert gas filling can achieve R-values as high as $10^{7}$.

- Retrofit plastic films consist of a laminated polypropylene film, with or without a low-e coating, that can be applied directly to an existing glass pane. The films are intended to reduce the shading coefficient and increase thermal resistance and are available on the open market. Depending on the film used, shading coefficients can be reduced 35 percent on single-pane units and 22 percent on double-pane ${ }^{*}$ Retrofit films generally decrease the visible transmittance of the original glazing.

\section{Solar Control Films}

Many solar control films are commercially available to retrofit existing windows. They may be low-e, tints, and/or reflective. Most retrofit films will improve the performance of the glazing but are typically not as effective as glass that is coated during manufacture. The $\mathrm{SC}_{c}$ and the $\mathrm{T}_{\text {vis }}$ are usually the target characteristics to be altered by adhering these films. All films, even those sold as clear, will affect the $T_{\text {vis }}$ to some extent. Correct installation and durability are two important issues when considering retrofit films.

\section{Plastic Glazings}

Plastics glazings were originally used for safety glass. They are less brittle and lighter in weight than glass, and they block essentially all UV radiation. Plastics are common for skylights where lightweight, safety glazing, or molded shapes are desirable. They can also be formed in structured and textured sheets. Many of the same coatings and additives discussed in this chapter can be applied to plastics. However, even though low-e coatings can be applied to

\footnotetext{
* The actual performance of a low-e coating varies in relation to the climate and placement of the coating within the glazing unit.
} 
plastic suspended films, they currently cannot be applied to plastics used as the structural glazing itself.

Plastic glazing deficiencies include degradation of the plastic over time and exposure to weather, greater thermal expansion, flammability, and low melting temperatures. These are important issues when considering plastic.

Several types of plastic glazings are currently available:

- Acrylic glazing has good light transmittance and longevity. It tends to be soft and easily scratched. It can be frosted for translucence and privacy. Typically it is used in skylights. Acrylic is easily molded to a variety of shapes.

- Polycarbonate is similar to acrylic, harder, and less likely to scratch. It is a UV-stabilized material for use in vertical and overhead glazing. It has added properties to optimize its strength and thermal characteristics.

- Fiber-reinforced plastic consists of a double layer of plastic combined with fiberglass mesh or insulation. It is commonly seen as corrugated roofing panels that offer a translucent and flexible protection. Panels filled with fiberglass insulation are often used where a high thermal resistance combined with translucent glazing is preferred. Exposed surfaces of some products may be susceptible to erosion.

\section{Gas Fills and Vacuums}

Historically, double- and triple-pane window voids were air-filled. Even though the air fill creates the insulating effect of multipane units, conduction and convective currents can develop. With the emergence of alternative gas fills, the heat transfer properties of multipaned glazings have decreased.

The most common alternative gas fills are inert gases. Many safe and naturally occurring gases have a significantly lower thermal conductivity than air. By hermetically sealing these gases between two layers of glass, the conductance of the window can be decreased. The most commonly used gas is argon, which is easily extracted from the atmosphere. Krypton is more effective, particularly in small spaces, but is more costly to obtain and use than argon. 
When combined with special coatings, gas-filled units can achieve very high insulating values. For small thickness, the replacement of air with argon can effectively add about R-1 to the unit performance. An ideal air space should be $0.5 \mathrm{in}$. The wider the thickness of the fill space, the less advantageous the alternatives to air become. If the airspace is too wide, convective currents can devel op within the multipane unit, minimizing its effectiveness.

An alternate to gas fill is creating a vacuum, or evacuated space, between the panes of glass. Although not fully developed, this system theoretically has no convective or conductive heat exchange between the panes of glass. The longterm integrity of the seals at the glass edges and the structural stability of the unit have not been perfected to make this a viable alternative. The seal must be able to keep air density within the unit to less than 1 millionth of normal atmospheric pressure. An air density of only 10 times this amount is sufficient to re-establish conduction to normal levels. The current technology consists of two panes of glass about a half millimeter apart with vacuum between the panes. Tiny invisible glass spheres or silica foam within the evacuated space keep the unit from collapsing. Note that even using a vacuum does not eliminate conduction through the window spacers, or prevent radiative exchange through the glazing, or decrease air infiltration.

Using transparent insulation has great potential for translucent and semitranslucent glazing with high R-values. Several types of transparent insulation are not currently available commercially; however, others have been used for many years. The three major types of transparent insulation (fiberglass, aerogel, and honeycomb) are described below.

- Translucent fiberglass insulation is sandwiched between two panels of reinforced fiberglass. The density and thickness can be changed to modify the properties of the product. This product is currently available.

- Aerogel is made from 4 percent silica foam and 96 percent air. Microscopic cells of foam entrap gas, preventing convection, but allowing light to pass. This material creates a haze due to the scattering of light from the air pockets. It has the potential of reaching R-20 per inch. Radiation and conduction through aerogel are also reduced. This product is available in Europe, and a similar product is being developed in the United States.

- Honeycomb or capillary structures absorb solar radiation and reradiate or transmit it directly indoors. Inner walls function like low-temperature wall heaters, creating a passive heating system. 


\section{Directionally Selective Materials}

Directionally selective materials reject or redirect incident solar radiation based on a geometric relationship between incoming light and the material. These glazings can redirect light to a predetermined location. Examples of these glazings are glass block, silk-screened glazings, prismatic devices, enclosed louvers, hol ographic films, and imbedded structures.

Frit is the most common angle-selective coating. Frit consists of a ceramic coating screen (translucent or opaque) printed in small patterns on a glass surface. The pattern used on the glass controls the light based on its angle of incidence. The color of frit controls the reflection or absorption and the control of view or visual privacy. Visual transparency can also be controlled by applying frit to both sides of the glass in such a way that at some angles it appears transparent, while at other angles it appears opaque. Angle-selective materials can be thought of as a series of fins or overhangs within a piece of glass, which filter or block light.

Prismatic systems redirect light by the principles of refraction. Refraction is the "bending" of light as it passes through a material. A common example is the apparent "bending" of a pencil as it is immersed in water. A common prismatic device is the Fresnel lens, made of microscopic prismatic materials embedded within the glass to focus light. Depending on the application, Fresnel lenses can focus light inward or outward. Other than Fresnel lenses, prismatic systems have limited commercial availability.

Another type of directionally selective glazing in the research and development stage is holographic films. Holographic films consist of diffractive structures of photopolymers or embossed films that are applied to glass to direct light deep into a space. Light is redirected and remixed as desired, or as a function of the angle of incidence and wavel ength of the light. If the film is applied to the upper portion of a pane of glass, light that falls on that area is redirected. Holographic devices work in a way similar to traditional light shelves but are able to redirect for desired light penetration. Holographic film offers reduced maintenance compared with light shelves, but does not provide shading of lower portions of glass. Glass will appear darker in areas where film is applied but will remain undistorted.

Current goals are to produce a product that will direct sunlight falling on the device toward the ceiling, deep into the room, which will reflect glare-free, diffused light into work spaces. 


\section{Switchable Optical Materials}

Switchable optical windows, or smart windows, have the ability to change their physical properties based on predetermined conditions. These chromogenic glazings (which have the ability to change states) can be altered either passively or actively. Where a change is desired, switchable materials can provide reduction of glare, privacy, daylight and solar control, and reduction of UV transmission. Most are still in the developmental stages and are not yet available for large-scale commercial projects.

In a hot climate these switchable glazings can modulate the intensity of incoming sunlight. When combined with continuous dimming controls, switchable materials may provide a significant benefit in reducing peak electrical demand for cooling and lighting energy in commercial buildings.

Switchable optical materials are of several types, each characterized by the means with which to control its properties, as summarized below.

- Photochromic materials change their properties as a function of light intensity. Sunglasses have used this technology for some time. The primary benefit is for visual comfort and glare control. Several skylight manufacturers now offer this option. Optical properties are changed as the metal halides in the glass are exposed to light. This creates a clouded appearance. As the absorptance increases, transmissivity decreases. The material reverts back to its original transparent state in the dark. Disadvantages with photochromics are that the threshold for change is fixed. Therefore, there is no seasonal selectivity to allow more solar gain in winter and less in summer. When activated, photochromics reduce only the visual transmittance, not the infrared, so much of the solar heat gain is unaffected.

- Thermochromic materials change properties as a function of temperature. Optical properties are changed as liquid- and gel-based materials or thinfilm solid-state devices are exposed to heat. The material reverts to its original state when cooled. In its exposed state, the material has a clouded appearance. As with photochromics, a disadvantage with thermochromics is that the threshold for change is fixed.

- Electrochromic materials change properties as a function of applied voltage. Properties range from colored, to intermediate, to bleached. These systems are more complex than thermo- and photochromic systems. The threshold for change can be altered in an existing unit, allowing for occupant, daily, 
and seasonal adjustment. Controls can be operated manually or linked directly to building operating systems. Electrochromic coatings can be put on various layers of single- or double-pane units, or combined with other glazings (with or without other coatings).

There are two major types of active electrochromic coatings: liquid crystal devices and solid-state devices.

- Liquid crystal molecules (which are randomly distributed, and scatter and absorb light) are suspended between two transparent conductor layers. When electrically charged, the molecules align and allow light to pass. The clear position requires a continuous charge of electricity to maintain transparency, making this product either on or off. This system does not alter the shading coefficient and therefore provides little energy savings potential. It is used primarily for privacy and glare control on interior applications. Although this option is currently on the market, its high cost makes it applicable only for specific uses. Liquid suspension is similar to liquid crystal but dims through a range of tints as a result of applied voltage. This system requires a continuous voltage in all stages.

- Solid-state metal devices have a layer of metal deposited, similar to low-e coatings. By applying low voltage, properties can change between clear and tinted and a variety of states in between. Unlike liquid crystal, disruption of power will not change the state, rather, a small applied voltage is necessary to make each phase change. 


\section{Window Assemblies}

Windows are a composition of components. Glass panes are sealed together to form I.G. (insulated glass) units. The I.G. units are sealed into a sash, and the sash is fastened to the frame. This chapter examines the various components of the window assembly.

Windows have the potential to be net energy producers. By correctly matching the window specification with the design conditions, the window will be able to thermally outperform adjacent walls while providing solar gain for heating (in cold seasons) and natural ventilation (in hot seasons).

Issues that require resolution include improved glazing assembly technologies and the lack of equivalent technologies in frames and spacers. While glazings have advanced remarkably over the past several years, frames and edges have not kept up and hinder the advancement of some of the more progressive window systems.

\section{Edges and Spacers}

Since a single-pane window with a metal frame has about the same overall Ufactor as a single glass pane alone, frame and glazing edge effects were of little concern before the introduction of multiple-pane, low-e, and gas-filled technologies. The recent expansion of thermally improved glazing options has impacted frame and spacer properties and the resulting U-factors. As a result, frame and spacer options have also multiplied as manufacturers offer improved designs.

Edges and spacers are the systems that hold together an I.G. unit. Spacers can be made of aluminum, steel, fiberglass, foam, or combinations of these materials. Aluminum spacers are the most commonly used and are typically sealed with a butyl or rubber sealant. Aluminum is a highly conductive material, however, and can be the weak link to a more efficient glazing system. Insulating and composite spacers made of butyl, rubber, and fiberglass are being developed along with metal spacers that are thermally broken or corrugated to slow heat transfer. In a residential wood window, the difference between a 
standard aluminum spacer and a true insulating spacer can increase the overall efficiency of the unit by 25 percent.

\section{Frames}

Window frames can be made of aluminum, steel, wood, vinyl, fiberglass, or composites of these materials. Wood, fiberglass, and vinyl frames are better insulators than their metal counterparts, although some aluminum frames are designed with internal thermal breaks that reduce the heat transfer through the frame. Composite frames may use two or more materials (e.g., aluminum-clad wood, vinyl-clad wood) to optimize their design and performance. Frame geometry, as well as material type, can affect thermal performance properties.

Frames account for a large portion of the heat transfer characteristics in the window assembly. For example, a wood frame super window with a center-ofglass thermal resistance of R-8 has an overall unit thermal resistance of about R-4.6. The type of frame assembly chosen impacts the thickness, weight, durability, and thermal characteristics of the unit. These should be considered, as well as the glazing type, when specifying a window unit.

Many types of window frames are available. Each type has its own characteristics that influence both energy performance and function.

- Wood frames are the most common in residential window assemblies, particularly in the midwestern, central, and eastern United States. They are typically easy to repair and maintain, and can last indefinitely. Wood frames are often clad with vinyl or aluminum to decrease the exterior maintenance required. Wood can be a composite, engineered (finger jointed or laminated), or solid depending on the design criteria.

- Aluminum frames are light, strong, durable, and easy to extrude into complex shapes. Aluminum is the most common frame type for commercial systems, particularly in the Southwest and California. A variety of finishes can be applied, such as milled, anodized, factory-baked, and polyvinyl chloride (PVC). Aluminum has a high thermal conductivity. Therefore, the more surface area, the more heat transfer. In cold climates, condensation and frost can represent a problem that, if not addressed, can cause failure of I.G. units. Aluminum extrusions allow for a small frame profile and are common on double- and single-hung units and sliders. Aluminum casements 
and awnings are less common because of the requirements for stiffness when in an extended position.

- Steel frames are found mostly in retrofit applications of buildings from the 1920s and 30s. They have been phased out over the years due to maintenance and thermal constraints. Steel windows must be painted. Also, even though steel is stronger than aluminum, it is more expensive. Steel has a high thermal conductivity, making it prone to condensation and thermal transfer.

- Plastic frames are generally made of (PVC). They have a slow rate of water absorption, high impact resistance, and good resistance to abrasions and chemicals. Plastics are extruded similarly to aluminum but require larger profiles to support glazing units and to prevent sag. Plastics are thermally expansive and may be brittle when cold. Frames designed with large hollow sections can have significant convection currents within the hollow frame. Smaller cells or insulating fills reduce this problem. The conductivity of plastics is low, making it one of the most energy-efficient frames widely available on the market.

- Fiberglass frames are currently available and are used commonly in Canada. They offer minimal thermal expansion and have the potential to eliminate sash sag which is typical in vinyl frames, and sticking due to expansion (typical of wood frames). R-values of fiberglass frames can be higher than other frame types. They typically have an insulating fiberglass core with a hard, durable exterior surface.

The characteristics of window assemblies, including glazing, frames, and spacers, can be compared using the National Fenestration Rating Council's ratings or with computer programs such as WINDOW 4. (SeeAppendix A.)

Table 4 shows representative U-factors for window glazing, frame, and spacer combinations under winter design conditions. Due to their orientation and their greater projected surface areas, domed (and other shaped), tilted, and horizontal skylights have significantly higher U-factors than do vertical windows of similar materials and opening sizes. The results presented are for 3- by 5-foot windows. The U-factors vary somewhat with window size. 
Table 4. Representative window U-Factors $\left(B t u / h r \cdot \mathrm{ft}^{2} \cdot{ }^{\circ} \mathrm{F}\right)$

\begin{tabular}{|c|c|c|c|}
\hline Glazing type and thickness (in.) & $\begin{array}{c}\text { Aluminum frame } \\
\text { without thermal } \\
\text { break (with } \\
\text { conventional } \\
\text { spacer) }\end{array}$ & $\begin{array}{c}\text { Aluminum frame } \\
\text { with thermal break } \\
\text { (with conventional } \\
\text { spacer) }\end{array}$ & $\begin{array}{l}\text { Wood or vinyl } \\
\text { frame (with } \\
\text { insulated } \\
\text { spacer) }\end{array}$ \\
\hline Single glass & 1.30 & 1.07 & Not available \\
\hline Double glass & 0.81 & 0.62 & 0.48 \\
\hline $\begin{array}{l}\text { Double glass }(e=0.20),{ }^{*} \\
1 / 2 \text {-in. air space }\end{array}$ & 0.70 & 0.52 & 0.39 \\
\hline $\begin{array}{l}\text { Double glass }(e=0.10) \text {, } \\
1 / 2 \text {-in. air space }\end{array}$ & 0.67 & 0.49 & 0.37 \\
\hline $\begin{array}{l}\text { Double glass }(e=0.20), \\
1 / 2 \text {-in. argon space }\end{array}$ & 0.64 & 0.46 & 0.34 \\
\hline $\begin{array}{l}\text { Triple glass }(e=0.10) \text { on two } \\
\text { panes, } 1 / 2 \text {-in. argon spaces }\end{array}$ & 0.53 & 0.36 & 0.23 \\
\hline $\begin{array}{l}\text { Quadruple glass }(\mathrm{e}=0.10) \text { on two } \\
\text { panes, } 1 / 4 \text {-in. krypton spaces }\end{array}$ & Not available & Not available & 0.22 \\
\hline
\end{tabular}

\section{Window Types}

The operation of a window or glass door will also affect its overall energy performance. Air infiltration and ventilation are the main concerns. The various operations do not in themselves affect the R-value, except that some types may not be available in all glass thicknesses.

Common window types are described below.

- Hinged windows types include casements, awnings, and hoppers. They provide more ventilation than sliding windows, and air flow can be controlled based on the direction of sash opening. The sash closes against compression weatherstripping at the frame, providing a lower air leakage rate than that of other window types. Some frame types lend themselves to casement design better than others.

- Sliding windows are single- and double-hung and horizontal sliders. They offer less overall ventilation due to the bypass type of system. Weatherstripping is a sweep type that typically allows more air leakage than compression types. 
- Pivot windows are similar to casements but rotate on a pivot rather than a hinge.

- Mullionless windows are often found in commercial applications. They typically consist of large expanses of glass butted together and sealed with a silicone compound. They are usually used in interior applications because they do not typically have good thermal attributes.

- Sliding doors act in a similar way to horizontal sliding windows. The necessary threshold, however, is difficult to weatherstrip effectively. The glass-to-frame ratio is large and therefore can have a higher performing overall glass R-value.

- Patio doors and French doors can be weatherstripped more effectively than sliding doors. French doors with multiple operable doors are difficult to seal, and infiltration can be a problem.

\section{Skylights}

Skylights are "windows" placed on the horizontal or sloped portion of a roof. Skylights allow more abundant amounts of light into a space than vertical glazing, but unless carefully designed, are often net-energy losers. A rule of thumb is that the more light allowed in, the more heat gain, and the more surface area, the more heat loss. In most instances, a smaller skylight within a splayed opening will accomplish the same lighting effect as a larger unit in a straight opening, but with reduced heat gain and loss.

Skylights are difficult to use efficiently because of their sloped placement. Unless very steeply sloped (toward the south), skylights can allow excessive solar heat gain in the summer months instead of the winter, when it is desirable. Exterior natural convection from a horizontal skylight transfers more heat than comparable vertical windows. Radiative heat loss to the sky can also exceed that in horizontal windows.

Skylights are available in glass (flat, tempered, laminated, reinforced) or plastic (acrylic, polycarbonate, fiberglass). Plastics offer the ability to be molded into many shapes, while glass offers a greater variety of performance characteristics. Each glazing material is available in single or multiple-paned units, and all standard frame types are available. Low-e coatings in a skylight are very effective at reducing heat loss. Tints and other coatings are also available. 
Operable units can, through natural convection, assist in the cooling of a building or space. 


\section{Fenestration Economics}

Naturally, one issue concerning the selection of a window is its cost. One can ask at what cost is the point of diminishing returns reached? How much can be spent on a window and still realize a reasonable return on investment? These questions are difficult to answer because of the many factors that must be considered. Building type, orientation, size, and climate are among the factors that must be evaluated.

The following two sections illustrate methodologies that can be employed to perform these analyses.

\section{BLAST Support Office Comparison Study}

Supported by CERL, the BSO (BLAST Support Office Building Loads Analysis and System Thermodynamics) at the University of Illinois Department of Mechanical and Industrial Engineering, conducted a study that compared three window types: double-pane, double-pane low-e, and double pane singlefilm Heat Mirror.

The BSO study compared the economic performance of the three window types for three envelope-dominated buildings in 10 weather locations in the continental United States.

Building models of a barracks, a regimental headquarters building, and a singlefamily housing unit were simulated. The windows in each model were changed to each of the three options for comparison purposes. The energy analysis was performed using the BLAST simulator, combined with glazing system results from WINDOW 4.1 (E.O. Lawrence Berkeley National Laboratory, 1994; see Appendix A). 
The results of the energy analysis were combined with economic data from LCCID* to produce life-cycle cost data on each of the options. The data used in the study are described below, along with the conclusions that were drawn.**

\section{Methodology}

Specifications of the window types that were evaluated are described below. (Codes are those used in the WINDOW program.)

- DBLE.W4, two panes of clear 3.2-mm Libbey-Owens-Ford glass with a 0.5in. airspace.

- DBLELOWE.W4, outer pane of 3.0-mm Energy Advantage Low-E clear glass from Libbey-Owens-F ord (long-wave emissivity, 0.197, inside surface), 0.5-in. airspace, and inner pane of clear 3.2-mm Libbey-Owens-Ford glass.

- DBLELEAR.W4, outer pane of 3.0-mm Energy Advantage Low-E clear glass from Libbey-Owens-F ord (long-wave emissivity, 0.197, inside surface), 0.5-in. gap with argon fill, and inner pane of clear 3.2-mm Libbey-Owens-Ford glass.

- DBLEHM66.W4, outer pane of clear 3.2-mm Libbey-Owens-Ford glass, 0.5in. airspace, Heat Mirror66 film, 0.5-in. airspace, and inner pane of clear 3.2$\mathrm{mm}$ Libbey-Owens-F ord glass.

The Heat Mirror products are all named for their transmissivity in the visible spectrum (i.e., for Heat Mirror66 film, the visible transmissivity is 0.66 ). They are all oriented such that their more reflective surface is toward the inside of the window system.

Each building and orientation was modeled as both new construction and retrofit, with three window options. Each model was then simulated, using BLAST, for each of six weather locations (Table 5). The resulting total annual energy use and annual electric use were then calculated for each location.

\footnotetext{
* "Life Cycle Cost in Design” (1996) U.S. Army Construction Engineering Research Laboratory, Champaign, IL.

${ }^{\text {** }}$ No variation in frames was considered; thus, only center-of-glass properties were used.
} 
Table 5. Weather regions/locations (U.S. Department of Energy) for BSO study

\begin{tabular}{|l|l|l|}
\hline Region & Location & Range (heating degree days) \\
\hline 5 & Minneapolis, MN & $9000-7000$ \\
\hline 6 & Denver, CO & $7000-5500$ \\
\hline 7 & $\begin{array}{l}\text { New York, NY; St. Louis, MO; Seattle, WA; } \\
\text { Washington DC }\end{array}$ & $5500-4000$ \\
\hline 8 & Atlanta, GA & $4000-2000$ \\
\hline 9 & Los Angeles, CA & $2000-0$ \\
\hline 10 & Phoenix, AZ; Miami, FL & $2000-0$ (cooling degree days > 2000) \\
\hline
\end{tabular}

The life-cycle savings from reduced energy use was determined for the low-e and Heat Mirror windows in comparison to plain double pane-windows. The amounts were calculated assuming a constant annual energy savings and life periods of 5, 10, 15, and 20 years. Economic analysis information was obtained from LCCID L92 (Fiscal Year [FY] 1995). The 3 percent discount rate for energy studies as determined by the Department of Energy (DOE) for FY95 was used. The energy prices used were the DOE list prices for the industrial sector by census region for FY95. They were used to determine the annual savings (in 1994 dollars) according to the equation

(Annual reduction in energy use) * (Price) $=$ Annual savings

The modified uniform present worth (UPW*) factors from October 1994 incorporate the constant discount rate and the differential fuel escalation rates for the life of the item studied, and also vary with census region. The total present worth of the energy savings provided by each alternative was calculated by the equation

(Annual savings) $*($ UPW*) $=$ Present worth of savings

Recurring maintenance and repair, and operation and maintenance, were assumed the same for all options and were not considered. Replacement cost is not considered since the windows are expected to last for the economic life of the building. Electrical demand charges were not taken into consideration.

\section{Results}

Examination of discounted energy savings per $100 \mathrm{ft}^{2}$ of glazing area shows some interesting trends. Most apparent is that the north-south-oriented barracks benefit the most from more energy-efficient windows. This is probably caused 
by the predominance of glazing on the east and west sides of the building, which receive the most sunlight at small polar angles of incidence.

The economic results of this study are summarized in Tables 6 and 7. These tables show the average discounted payback and the minimum discounted payback from fuel savings per $100 \mathrm{ft}^{2}$ of glazing, sorted by weather region. The low-e windows apparently perform better in the colder climates (regions 5-7). Not unexpectedly, the Heat Mirror windows perform well in the hotter climates (regions 8-10).

Table 6. Present worth of 5 years of energy savings per $100 \mathrm{ft}^{2}$ of glazing

\begin{tabular}{|l|c|c|c|c|}
\hline \multirow{2}{*}{$\begin{array}{c}\text { Weather } \\
\text { region }\end{array}$} & \multicolumn{2}{|c|}{ Low-e versus double pane } & \multicolumn{2}{c|}{ Heat Mirror versus double pane } \\
\cline { 2 - 5 } & $\begin{array}{c}\text { Average Discounted } \\
\text { Payback }\end{array}$ & $\begin{array}{c}\text { Minimum Discounted } \\
\text { Payback }\end{array}$ & $\begin{array}{c}\text { Average Discounted } \\
\text { Payback }\end{array}$ & $\begin{array}{c}\text { Minimum Discounted } \\
\text { Payback }\end{array}$ \\
\hline 5 & $\$ 99.52$ & $\$ 83.85$ & $\$ 172.36$ & $\$ 111.14$ \\
\hline 6 & $\$ 72.83$ & $\$ 56.11$ & $\$ 130.35$ & $\$ 97.64$ \\
\hline 7 & $\$ 71.55$ & $\$ 41.26$ & $\$ 128.18$ & $\$ 75.83$ \\
\hline 8 & $\$ 55.77$ & $\$ 39.45$ & $\$ 174.96$ & $\$ 111.49$ \\
\hline 9 & $\$ 31.66$ & $\$ 18.71$ & $\$ 155.86$ & $\$ 75.27$ \\
\hline 10 & $\$ 58.71$ & $\$ 26.10$ & $\$ 211.25$ & $\$ 112.26$ \\
\hline
\end{tabular}

Table 7. Present worth of 10 years of energy savings per $100 \mathrm{ft}^{2}$ of glazing

\begin{tabular}{|l|c|c|c|c|}
\hline \multirow{2}{*}{$\begin{array}{c}\text { Weather } \\
\text { region }\end{array}$} & \multicolumn{2}{|c|}{ Low-e versus double pane } & \multicolumn{2}{c|}{ Heat Mirror versus double pane } \\
\cline { 2 - 5 } & $\begin{array}{c}\text { Average Discounted } \\
\text { Payback }\end{array}$ & $\begin{array}{c}\text { Minimum Discounted } \\
\text { Payback }\end{array}$ & $\begin{array}{c}\text { Average Discounted } \\
\text { Payback }\end{array}$ & $\begin{array}{c}\text { Minimum Discounted } \\
\text { Payback }\end{array}$ \\
\hline 5 & $\$ 192.13$ & $\$ 162.69$ & $\$ 331.96$ & $\$ 214.58$ \\
\hline 6 & $\$ 139.95$ & $\$ 107.52$ & $\$ 249.40$ & $\$ 186.92$ \\
\hline 7 & $\$ 137.47$ & $\$ 79.76$ & $\$ 245.34$ & $\$ 145.58$ \\
\hline 8 & $\$ 106.32$ & $\$ 76.07$ & $\$ 330.01$ & $\$ 210.36$ \\
\hline 10 & $\$ 59.73$ & $\$ 34.95$ & $\$ 291.81$ & $\$ 139.03$ \\
\hline
\end{tabular}

\section{BSO Study Conclusions}

If the initial cost difference between double pane, double pane low-e, and double pane Heat Mirror windows is known, this analysis can be used to make an educated design decision on the economy of the options, based on weather region and desired payback period.

For example, if an office building to be built in weather region 6 has a price difference of $\$ 40$ per $100 \mathrm{ft}^{2}$ of glazing between ordinary double pane and low-e windows, and a price difference of $\$ 80$ between ordinary double pane and Heat Mirror windows, then from the above table, the probable minimum life-cycle savings over 5 years is calculated as follows: 
Low-e $\$ 56.11$ - $\$ 40.00=\$ 16.11$ per $100 \mathrm{ft}^{2}$ glazing

Heat Mirror $\$ 97.64-\$ 80.00=\$ 17.64$ per $100 \mathrm{ft}^{2}$ glazing

So, in this example, the Heat Mirror windows (with greater life-cycle savings) would be a slightly better buy.

As a second example, the same prices apply to a building in region 9 .

Low-e $\$ 18.71-\$ 40.00=\quad-\$ 21.29$ per $100 \mathrm{ft}^{2}$ glazing

Heat Mirror $\$ 75.27-\$ 80.00=-\$ 4.73$ per $100 \mathrm{ft}^{2}$ glazing

The plain double pane windows would be the likely option if a near-certain payback in 5 years was desired. However, the payback period is allowed to be 10 years, the following results apply:

$$
\begin{aligned}
& \text { Low-e } \$ 34.95-\$ 40.00=\quad \$ 5.05 \text { per } 100 \mathrm{ft}^{2} \text { glazing } \\
& \text { Heat Mirror } \$ 139.03-\$ 80.00=\$ 59.03 \text { per } 100 \mathrm{ft}^{2} \text { glazing }
\end{aligned}
$$

Thus, a 10-year payback period clearly favors the Heat Mirror windows in this case.

Although this study looked at many different options to try to characterize the economic characteristics of double pane, double pane low-e, and double pane Heat Mirror windows, it is still recommended to perform a full energy analysis on each building to obtain more accurate results for each specific case encountered. Many variables, including building size, location, orientation, HVAC systems and controls, internal loads, infiltration, and construction can affect the annual energy performance of a building, and therefore the cost effectiveness of various window systems.

\section{ENSAR Reglazing Analysis Case Study}

Examples of real projects are often excellent tools for understanding relevant issues of design process. In this case, the process of analyzing options for reglazing a high-rise office building is summarized. 
This example is a study of reglazing options for a 13-story office tower in a Chicago suburb. The building, constructed in 1974, is 200,200 gross $\mathrm{ft}^{2}$ of floor area. In 1994 the building was vacated, and the interior finishes and mechanical systems were removed to prepare for new tenant buildouts.

A brief evaluation of the building revealed that several of the original window glazing (insulated glass) units had reached their anticipated life (about 20 years) and were failing. A feasibility study was conducted on the economics of reglazing the entire building, as opposed to replacing smaller failed groups of 30 or 50 at a time. The analysis entailed the following methodology: develop a problem statement, identify a range of solutions, evaluate energy performance results, evaluate glazing costs, evaluate life-cycle cost analysis, and establish design strategies.

\section{Problem Statement}

The 13-story building has four identical facades (Figure 7). The first-floor glazing system is unique and was considered as a separate analysis. Each of the 12 floors analyzed comprise 72 I.G. window units ( $4 \mathrm{ft}, 8 \mathrm{in}$. by $6 \mathrm{ft}, 0 \mathrm{in}$.) for a total of 864 glazing units and $24,209 \mathrm{ft}^{2}$ of glazing.

Each existing I.G. unit is constructed of a $1 / 4$-in. bronze-tinted outer lite and a $1 / 4-$ in. clear glass inner lite for a 1-in. total glazing thickness in a standard aluminum frame. The interior surface of the units has an applied film coating (most likely to reduce solar heat gains and improve thermal comfort). The "center-of-glass" winter U-value is 0.47 , the shading coefficient $\left(\mathrm{SC}_{c}\right)$ is 0.28 , and the visible light transmittance $\left(T_{\text {vis }}\right)$ is 9 percent.



Figure 7. Typical floor plan. 


\section{A baseline condition was established using empirical data and data assumptions for modeling purposes. Table 8 is a summary of the baseline condition.}

Table 8. Baseline condition (ENSAR case study).

\begin{tabular}{|c|c|c|}
\hline Component & Parameter & Value \\
\hline Floor area & $200,200 \mathrm{ft}^{2}$ gross & $189,856 \mathrm{ft}^{2}$ \\
\hline \multirow[t]{8}{*}{ Envelope } & Wall insulation & R-11 batt \\
\hline & Roof insulation & $\mathrm{R}-19$ rigid \\
\hline & Floor-to-ceiling height & 9 \\
\hline & Floor-to-floor height & 13 \\
\hline & Window U-factors & $\begin{array}{l}0.47 \text { center-of-glass (floors } 2-13, \mathrm{dbl} \text { pane bronze with sun control film) } \\
0.95 \text { center-of-glass (first floor, single pane bronze with sun control film }\end{array}$ \\
\hline & $\begin{array}{l}\text { Window shading } \\
\text { coefficient }(S C)\end{array}$ & $\begin{array}{l}0.28 \text { (floors } 2-13 \text { ) } \\
0.30 \text { (first floor) }\end{array}$ \\
\hline & $\begin{array}{l}\text { Window Visible } \\
\text { Transmissivity }\left(T^{\text {vis }}\right)\end{array}$ & $\begin{array}{l}0.90 \text { (floors } 2-13 \text { ) } \\
0.10 \text { (first floor) }\end{array}$ \\
\hline & Infiltration rates & 0.1 air changes/hr (perimeter only) \\
\hline \multirow[t]{3}{*}{$\begin{array}{l}\text { Internal } \\
\text { loads }\end{array}$} & $\begin{array}{l}\text { Lighting power } \\
\text { density }\end{array}$ & $1.28 \mathrm{~W} / \mathrm{ft}^{2}$ (average) \\
\hline & $\begin{array}{l}\text { Plug load power } \\
\text { density }\end{array}$ & $1.1 \mathrm{~W} / \mathrm{ft}^{2}$ \\
\hline & Occupant density & $200 \mathrm{ft}^{2} /$ person \\
\hline \multirow[t]{14}{*}{ HVAC } & Cooling system & Central chilled water plant with centrifugal chillers \\
\hline & Heating system & Electric terminal reheat coils \\
\hline & Fan system & Central station variable air volume with terminal fan-powered boxes \\
\hline & Heating efficiency & $100 \%$ (electric resistance preheat and reheat coils) \\
\hline & Chiller efficiency & $0.94 \mathrm{~kW} / \mathrm{ton}$ \\
\hline & $\begin{array}{l}\text { Total chilled water } \\
\text { plant efficiency }\end{array}$ & $1.18 \mathrm{~kW} /$ ton \\
\hline & Fan power & $\begin{array}{l}224 \text { kW (supply) } \\
75 \mathrm{~kW} \text { (return) } \\
63 \mathrm{~kW} \text { (terminal fan boxes) }\end{array}$ \\
\hline & Fan supply air volume & $190,000 \mathrm{ft}^{3} / \mathrm{min}$ \\
\hline & Air-side economized & Dry bub control \\
\hline & Thermostat setpoints & $\begin{array}{l}\text { 72/62 }{ }^{\circ} \mathrm{F} \text { (heating-occupied/unoccuptied) } \\
76 / 85^{\circ} \mathrm{F} \text { (cooling occupied/unoccupied) }\end{array}$ \\
\hline & Ventilation rates & $20 \%$ outside air fraction \\
\hline & Fan schedule & $\begin{array}{l}6 \text { am - 10pm (weekday) } \\
\text { 8am - 4pm (Saturday) }\end{array}$ \\
\hline & $\begin{array}{l}\text { Service hot water } \\
\text { load }\end{array}$ & $120 \mathrm{Btu} / \mathrm{hr} /$ person \\
\hline & Cooling capacity & 750 tons \\
\hline
\end{tabular}


The baseline condition was then simulated using the Department of Energy's DOE-2 energy analysis program. Results of this model indicate that the building can typically consume $67.6 \mathrm{kBtu} / \mathrm{ft}^{2} / \mathrm{yr}$ of onsite energy. As illustrated in Figure 8, space cooling consumes 15 percent of the total site energy use. Lighting systems use about 27 percent, fans 24 percent, plug loads approximately 16 percent, and space heating accounts for about 14 percent of the total annual energy use. Elevators (3 percent) and service water heating (1 percent) consume the balance.

The peak electric demand for the baseline condition was modeled at 1,252 kW, or 6.6 W/net $\mathrm{ft}^{2}$ and the annual utility cost is estimated at $\$ 285,247$.

\section{Solutions}

A range of glazing solutions were then identified in response to the baseline energy consumption patterns. The system parametrics were also evaluated using sensitivity analysis. Sensitivity analysis is a way to test the sensitivity of discrete variables, typically by modifying distinct variables until they are no longer a contributing factor in the analysis. For example, the $\mathrm{SC}_{c^{\prime}} \mathrm{T}_{\text {vis, }}$ or $\mathrm{U}$ value can be modified or factored out of the baseline model, to test the sensitivity of other energy consumption variables.

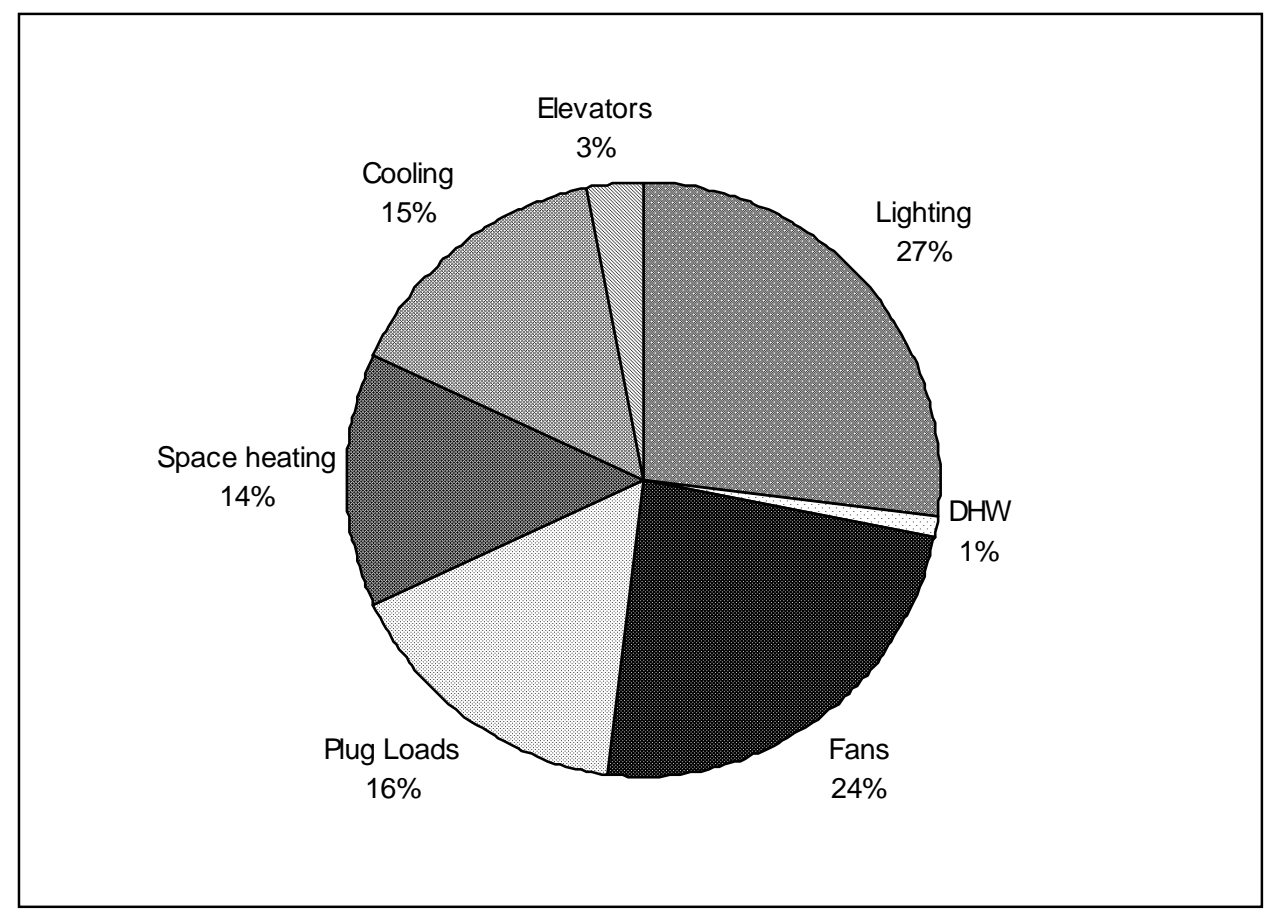

Figure 8. Energy use breakdown. 
This analysis includes six glazing options, a daylighting control strategy, and a combination of aggressive energy efficiency measures. The glazing options include the following: A - I.G. bronze tint with low-e coating; B - I.G. clear with selective low-e coating; C - I.G. bronze tint with a selective low-e coating; D - I.G. bronze with a low-e coating on a suspended film; E - I.G. green tint with a low-e coating on a suspended film; and F - an I.G. aqua tint with double-sided low-e suspended film and a gas fill. The performance characteristics are listed in Table 9.

Daylight transmittance is an important variable. Increased daylighting can reduce the electric lighting load, the cooling load, and the electrical peak demand. Since the lighting load represents 27 percent of the total annual energy use, daylighting strategies were considered. For modeling purposes, it was assumed that photocell controls would be used to keep lighting levels constant. This type of control uses sensors to determine the natural light available and the amount of electrical lighting needed to keep the room at preferred lighting levels.

Glazing options were also evaluated individually and combined with a more aggressive energy conservation package (which uses a more effective daylighting solution and high-efficiency electric lighting, office equipment, and HVAC equipment) to examine the effects of the holistic conservation approach. As noted previously, cost savings in one area can help offset investments in other areas, if the entire system is evaluated as a whole instead of as individual systems.

Table 9. Glazing characteristics.

\begin{tabular}{|l|c|c|c|c|c|c|c|}
\hline Case & $\begin{array}{l}\text { U-Value } \\
\text { (summer) }\end{array}$ & $\begin{array}{l}\text { U-Value } \\
\text { (winter) }\end{array}$ & $\boldsymbol{T}_{\text {vis }}(\%)$ & $\boldsymbol{S C}_{c}$ & $\boldsymbol{K}_{\boldsymbol{e}}$ & SHGF $_{c}$ & $\begin{array}{l}\text { Relative } \\
\text { SHG }\end{array}$ \\
\hline A - Base Case (bronze/film) & 0.47 & & 9 & 0.3 & 0.32 & 0.24 & \\
\hline B - Clear low-e VE1-40 & 0.29 & 0.27 & 36 & 0.3 & 1.16 & 0.27 & 68 \\
\hline C - Bronze low-e VE4-55 & 0.32 & 0.34 & 28 & 0.3 & 0.88 & 0.28 & 64 \\
\hline D - Bronze HM66 & 0.29 & 0.24 & 42 & 0.4 & 1.14 & 0.32 & 73 \\
\hline E - Green HM66 & 0.36 & 0.30 & 45 & 0.3 & 1.50 & 0.26 & 69 \\
\hline F - Azurite HM TC88 gas & 0.14 & 0.12 & 51 & 0.3 & 2.04 & 0.21 & 54 \\
\hline
\end{tabular}




\section{Energy Performance Results}

The baseline condition and the six glazing options were analyzed using a DOE-2 computer simulation of the building. Results (compared to the baseline condition) are in terms of an energy use index (kBtu/ft²/year), peak building electrical demand, peak cooling load, and annual electric costs and savings. As summarized in Table 10, the results allow a preliminary sorting of the energy performance and economics of the six modeled glazing options.

\section{Glazing Costs}

Bids were solicited for each of the 6 glazing options. I nstallation costs reviewed in Table 11 represent the average of bids received from five contractors in the Chicago area for each option. The options for total reglazing ranged from $\$ 11.07 / \mathrm{ft}^{2}$ for case $\mathrm{B}$ to $\$ 18.52 / \mathrm{ft}^{2}$ for case $\mathrm{F}$. (N ote that the highest cost per unit $\left[\$ 22.60 / \mathrm{ft}^{2}\right]$ is the typical method of replacing glazed units as they fail.)

A conservative estimate for the replacement rate of existing glazing was established. It was assumed that half of the units that have not already been replaced will be replaced within a 10-year period (about 46 units per year at $\$ 33,810$ per year). Since a group replacement recently took place, it was assumed that the next group replacement would start in year 2 .

As noted, daylighting is a key component in glazing retrofit strategies. In this analysis, the installation of photocell controls were included in the reglazing cost options. Table 11 shows ranges of $\$ 312,500$ to $\$ 492,812$ for the total installation costs of reglazing and daylighting controls.

Table 10. Energy performance-compared with existing conditions.

\begin{tabular}{|c|c|c|c|c|c|c|c|}
\hline Case & $\begin{array}{c}\text { Energy Use } \\
\text { Index } \\
\text { (kBtu/ft'/year) }\end{array}$ & $\begin{array}{l}\text { Peak building } \\
\text { demand } \\
\text { reduction }(\mathrm{kW})\end{array}$ & $\begin{array}{l}\text { Peak cooling } \\
\text { load reduction } \\
\text { (tons) }\end{array}$ & $\begin{array}{c}\text { Annual } \\
\text { electric bill } \\
\text { (\$/year) }\end{array}$ & $\begin{array}{c}\text { Annual energy } \\
\text { savings } \\
\text { (\$/year) }\end{array}$ & $\begin{array}{c}\text { Cost of } \\
\text { measure } \\
(\$)\end{array}$ & $\begin{array}{c}\text { Simple } \\
\text { payback } \\
\text { period } \\
\text { (years) }\end{array}$ \\
\hline $\begin{array}{l}\text { A - Base case } \\
\text { (bronze/film) }\end{array}$ & 67.9 & 0 & 0 & 285,247 & 0 & 0 & 0 \\
\hline $\begin{array}{l}\text { B - Clear low-e } \\
\text { VE1-40 }\end{array}$ & 61.7 & 9 & -1 & 272,619 & 12,628 & 312,500 & 24.7 \\
\hline $\begin{array}{l}\text { C - Bronze low-e } \\
\text { VE4-55 }\end{array}$ & 61.9 & 4 & -4 & 273,532 & 11,715 & 325,500 & 27.8 \\
\hline D - Bronze HM66 & 61.1 & 74 & 8 & 260,418 & 24,829 & 448,260 & 18.0 \\
\hline E - Green HM66 & 61.7 & 67 & 9 & 258,505 & 26,742 & 458,500 & 26.7 \\
\hline $\begin{array}{l}\text { F - Azurite HM } \\
\text { TC88 gas }\end{array}$ & 55.9 & 81 & 7 & 245,328 & 39,328 & 492,810 & 12.5 \\
\hline
\end{tabular}


Table 11. Installation cost.

\begin{tabular}{|c|c|c|c|c|c|c|}
\hline Case & $\begin{array}{l}\text { Installed } \\
\text { glazing } \\
\text { cost } \\
\left(\$ / \mathrm{ft}^{2}\right)^{\star}\end{array}$ & $\begin{array}{l}\text { Incremental } \\
\text { glazing cost } \\
\text { (based on } \\
\text { case } B) \\
\left(\$ / \mathrm{ft}^{2}\right)\end{array}$ & $\begin{array}{c}\text { Total glazing } \\
\text { cost }\left(24,209 \mathrm{ft}^{2}\right) \\
\left(\$ / \mathrm{ft}^{2}\right)\end{array}$ & $\begin{array}{l}\text { Daylighting } \\
\text { controls (\$) }\end{array}$ & $\begin{array}{c}\text { Total } \\
\text { installation } \\
\text { cost }(\$)\end{array}$ & $\begin{array}{l}\text { Incremental } \\
\text { first cost } \\
\text { (based on } \\
\text { case B) (\$) }\end{array}$ \\
\hline $\begin{array}{l}\text { A - Base case } \\
\text { (bronze/film) }\end{array}$ & 22.60 & 11.53 & $50,165^{\star *}$ & 0 & $50,165^{\star *}$ & $N / A^{* * *}$ \\
\hline $\begin{array}{l}\text { B - Clear low-e } \\
\text { VE1-40 }\end{array}$ & 11.07 & 0 & 268,000 & 44,500 & 312,500 & 0 \\
\hline $\begin{array}{l}\text { C - Bronze low-e } \\
\text { VE4-55 }\end{array}$ & 11.61 & 0.54 & 281,000 & 44,500 & 325,500 & 13,000 \\
\hline D - Bronze HM66 & 16.68 & 5.61 & 403,768 & 44,500 & 448,268 & 135,768 \\
\hline E - Green HM66 & 17.10 & 6.03 & 414,000 & 44,500 & 458,500 & 146,000 \\
\hline $\begin{array}{l}\text { F - Auzurite HM } \\
\text { TC88 gas }\end{array}$ & 18.52 & 7.45 & 448,312 & 44,500 & 492,812 & 180,312 \\
\hline \multicolumn{7}{|c|}{$\begin{array}{l}\text { * Average of five bids from glazing contractors. } \\
{ }^{* *} \text { The annual replacement cost after the first year is } \$ 50,165 / \text { year ( } 79 \text { units/year @ } \$ 635 / \text { unit) due to the assumed } \\
\text { continued failures in existing glazing. } \\
{ }^{* \star *} \text { Because the replacement cost for case A happens annually, the incremental first cost is not applicable }\end{array}$} \\
\hline
\end{tabular}

\section{Life Cycle Analysis}

The long-term consequences of the reglazing strategies were evaluated using a simple life-cycle analysis. This analysis includes energy operating costs and investment costs of the reglazing, daylighting controls, electric lighting, HVAC equipment, and other components of the aggressive retrofit package. It does not include present value conversions, discount rates, fuel escalation rates, added real estate value, or other factors of a more rigorous analysis.

Ten- and twenty-year life-cycle cost analyses were conducted (Table 12). For the base case, replacement of failed glazings was assumed to cost $\$ 34,000$ per year after the first year. In year 3, the owners plan to replace the old chiller equipment at a cost of approximately $\$ 600,000$ (750 tons @ \$800/ton, present value). The annual operating cost is estimated at $\$ 285,000$ per year.

For cases B-F, the respective reglazing costs were added to an aggressive complete retrofit package ( $\$ 560,000$ net cost with design integration) for the first-year investment costs. The 10-year analysis shows the total cost to be $\$ 3,756,000$ for the base case (A). As shown in Table 12, the five reglazing options (10-year analysis) range from $\$ 1,977,000$ to $\$ 2,080,000$. The least cost for the 10-year life-cycle is case $F$, for a total of $\$ 1,977,000$ (saving $\$ 1,779,000$ over the base case). 
Table 12. Simple life-cycle analysis.

\begin{tabular}{|c|c|c|c|c|c|c|c|c|c|c|c|c|c|c|c|}
\hline & \multirow{3}{*}{ Case* $^{\star}$} & \multicolumn{14}{|c|}{ Cost (thousands of dollars) } \\
\hline & & \multicolumn{10}{|c|}{ Year } & \multirow{2}{*}{$\begin{array}{c}\text { Total } \\
\text { (Years 1-10) } \\
\end{array}$} & \multirow{2}{*}{$\begin{array}{l}\text { Years } \\
11-19 \\
\end{array}$} & \multirow{2}{*}{$\begin{array}{l}\text { Year } \\
20 \\
\end{array}$} & \multirow{2}{*}{$\begin{array}{c}\text { Total } \\
\text { (Years 1-20) } \\
\end{array}$} \\
\hline & & 1 & 2 & 3 & 4 & 5 & 6 & 7 & 8 & 9 & 10 & & & & \\
\hline \multirow{3}{*}{ A } & Investment & 0 & 34 & 634 & 34 & 34 & 34 & 34 & 34 & 34 & 34 & 906 & 34 & 34 & 1,246 \\
\hline & Energy & 285 & 285 & 285 & 285 & 285 & 285 & 285 & 285 & 285 & 285 & 2,850 & 285 & 285 & 5,700 \\
\hline & Total & 285 & 319 & 919 & 319 & 319 & 319 & 319 & 319 & 319 & 319 & 3,756 & 319 & 319 & 6,946 \\
\hline \multirow{3}{*}{ B } & Investment & 837 & & 160 & & & & & & & & 997 & & 34 & 1,031 \\
\hline & Energy & 106 & 106 & 106 & 106 & 106 & 106 & 106 & 106 & 106 & 106 & 1,060 & 106 & 106 & 2,120 \\
\hline & Total & 943 & 106 & 266 & 106 & 106 & 106 & 106 & 106 & 106 & 106 & 2,057 & 106 & 140 & 3,151 \\
\hline \multirow{3}{*}{ C } & Investment & 850 & & 160 & & & & & & & & 1,010 & & 34 & 1,044 \\
\hline & Energy & 107 & 107 & 107 & 107 & 107 & 107 & 107 & 107 & 107 & 107 & 1,070 & 107 & 107 & 2,140 \\
\hline & Total & 957 & 107 & 267 & 107 & 107 & 107 & 107 & 107 & 107 & 107 & 2,080 & 107 & 141 & 3,184 \\
\hline \multirow{3}{*}{ D } & Investment & 972 & & 160 & & & & & & & & 1,132 & & 34 & 1,166 \\
\hline & Energy & 94 & 94 & 94 & 94 & 94 & 94 & 94 & 94 & 94 & 94 & 940 & 94 & 94 & 1,880 \\
\hline & Total & 1066 & 94 & 254 & 94 & 94 & 94 & 94 & 94 & 94 & 94 & 2,072 & 94 & 128 & 3,046 \\
\hline \multirow{3}{*}{$\mathbf{E}$} & Investment & 983 & & 160 & & & & & & & & 1,143 & & 34 & 1,117 \\
\hline & Energy & 92 & 92 & 92 & 92 & 92 & 92 & 92 & 92 & 92 & 92 & 920 & 92 & 92 & 1,840 \\
\hline & Total & 1075 & 92 & 252 & 92 & 92 & 92 & 92 & 92 & 92 & 92 & 2,063 & 92 & 126 & 3,017 \\
\hline \multirow{3}{*}{$\mathbf{F}$} & Investment & 1017 & & 160 & & & & & & & & 1,177 & & 34 & 1,211 \\
\hline & Energy & 80 & 80 & 80 & 80 & 80 & 80 & 80 & 80 & 80 & 80 & 800 & 80 & 80 & 1,600 \\
\hline & Total & 1097 & 80 & 240 & 80 & 80 & 80 & 80 & 80 & 80 & 80 & 1,977 & 80 & 114 & 2,811 \\
\hline & $\begin{array}{l}\text { se } A \text { (Base } c \\
\text { se } B=\text { Clear } \\
\text { se } C=\text { Bronz } \\
\text { se } D=H M 66 \\
\text { se } E=\text { Green } \\
\text { se } F=\text { Azurit }\end{array}$ & $\begin{array}{l}\text { = Bro } \\
\text {-e VE1 } \\
\text { w-e VE } \\
\text { M66 } \\
\text { C88 gas }\end{array}$ & $\begin{array}{l}\text { ze/film } \\
0 \\
-55\end{array}$ & & & & & & & & & & & & \\
\hline
\end{tabular}

The 20-year analysis shows the total cost to be $\$ 6,946,000$ for the base case (A). Cost of the other options ranges from $\$ 2,811,000$ to $\$ 3,184,000$. The least cost for the 20-year life-cycle is option F, with a total cost of $\$ 2,811,000$ (saving $\$ 4,135,000$ over the base).

\section{Design Strategies}

Sufficient information is now available to rank and select an appropriate glazing strategy. As with design decisions in general, there is not one "right" answer, but several that solve the problem. Table 13 describes selection rankings related to initial investment of glazing cost, annual electric bill, glazing light-toheat ratio, glazing cost, simple payback periods, and life-cycle cost. 
Table 13. Selection ranking

\begin{tabular}{|c|c|c|c|c|c|c|c|c|c|c|c|c|c|c|}
\hline \multirow[b]{2}{*}{ Case* $^{*}$} & \multicolumn{2}{|c|}{$\begin{array}{l}\text { Initial investment } \\
\text { of glazing cost }\end{array}$} & \multicolumn{2}{|c|}{$\begin{array}{c}\text { Annual electric } \\
\text { bill }\end{array}$} & \multicolumn{2}{|c|}{$\begin{array}{l}\text { Glazing heat- } \\
\text { to-light ratio }\end{array}$} & \multicolumn{2}{|c|}{ Glazing cost } & \multicolumn{2}{|c|}{$\begin{array}{c}\text { Simple } \\
\text { payback } \\
\text { period }\end{array}$} & \multicolumn{4}{|c|}{ Life -cycle-cost } \\
\hline & $\$$ & Rank & $\$$ & Rank & $\mathrm{K}$ & Rank & $\$ / \mathrm{ft}^{2}$ & Rank & Year & Rank & $\$$ & Rank & $\$$ & Rank \\
\hline$A$ & 50,165 & 1 & 285,247 & 7 & 0.32 & 7 & 22.6 & 7 & 0 & 1 & 3,756 & 7 & 6,946 & 7 \\
\hline$B$ & 312,500 & 2 & 272,619 & 5 & 1.16 & 3 & 11.07 & 2 & 24.7 & 5 & 2,057 & 3 & 3,151 & 5 \\
\hline $\mathrm{C}$ & 325,500 & 3 & 272,532 & 6 & 0.88 & 6 & 11.61 & 3 & 27.8 & 7 & 2,080 & 6 & 3,184 & 6 \\
\hline $\mathrm{D}$ & 448,268 & 4 & 260,418 & 3 & 1.14 & 4 & 16.68 & 4 & 18.0 & 4 & 2,072 & 5 & 3,046 & 4 \\
\hline $\mathrm{D}$ & 458,500 & 5 & 258,505 & 2 & 1.50 & 2 & 17.1 & 5 & 26.7 & 6 & 2,063 & 4 & 3,017 & 3 \\
\hline$E$ & 492,812 & 6 & 245,919 & 1 & 2.04 & 1 & 18.52 & 6 & 12.5 & 3 & 1,977 & 2 & 2,811 & 1 \\
\hline
\end{tabular}

The short-term solution, which receives the highest ranking based on initial investment only, is the base case ( $\mathrm{A}$ - replacing glazing as needed). This is the solution that some real-estate developers ascribe to because of the low initial investment, an average of $\$ 50,165$ per year. Of the other five options, clear, selective low-e (case B) has the lowest initial investment cost $(\$ 312,500)$. The most expensive initial cost $(F)$ is $\$ 492,812$.

The energy savings evaluation finds case $F$ with the lowest annual electric bill, $\$ 245,919$, compared with a base case cost of $\$ 285,247$ per year. For case $F$, this translates to annual energy savings of $\$ 39,328$ (Figure 9).

The initial energy use breakdown showed lighting and cooling energy usage to be 42 percent of the total annual use. This reflects the importance of the ratio of daylight transmittance to solar heat gain, $\mathrm{K}_{\mathrm{e}}$. The glazing retrofit option with the best coolness index is option $F\left(K_{e}=2.04\right)$ (Table 13). Compared with the base case of 0.32 , this glazing offers roughly five times the amount of daylight as the base case with about the same solar heat gain.

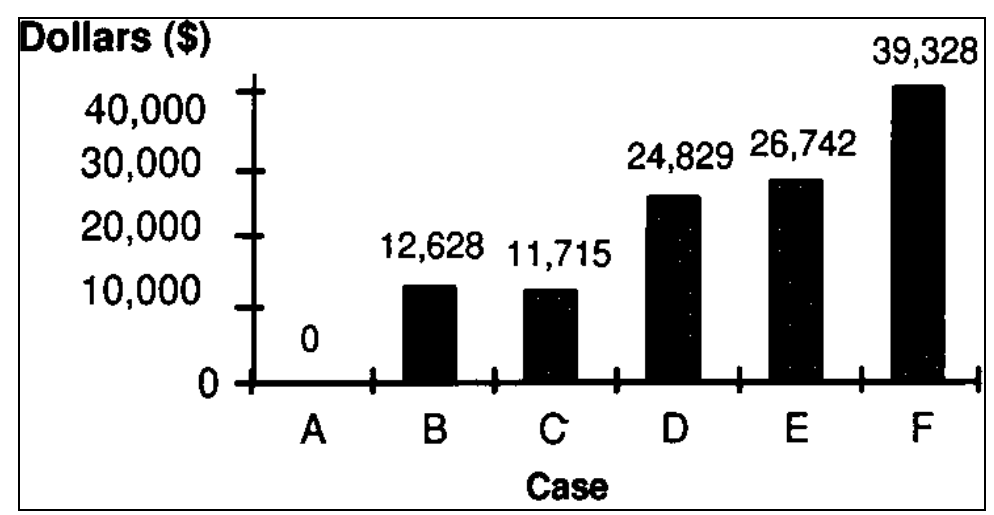

Figure 9. Annual energy savings. 
Figure 10 shows the that the option with the lowest glazing cost per square foot is clear, selective low-e glass (case $B$ ) at $\$ 11.07 / \mathrm{ft}^{2}$. It is closely followed by case C (bronze selective low-e) at $\$ 11.61 / \mathrm{ft}^{2}$. Both provide adequate daylight opportunities at reasonable prices.

The 10- and 20-year simple life-cycle cost analyses provide a more accurate tool for glazing selection. Ten year or less time periods are important to commercial and corporate building owners, who wish to effectively lower operating costs and improve short-term profits. Twenty year time periods are considered for public buildings where ownership is likely to be long-term. In this case, the commercial ownership has an interest in less than a ten year time period, 3 to 5 years is of most concern.

The most cost effective option for both the 10- and 20-year analyses is case $F$ (Figures 11 and 12). In 10 years, the simple life-cycle cost savings for case $F$ (compared with the base case) total $\$ 1,779,000$; in 20 years, the savings total $\$ 4,135,000$. Equally important is that the total investment and energy costs are less in case $F$ than the base case $A$ within a 3-year period. Thus, the simple lifecycle analysis produces a payback period of less than 3 years.

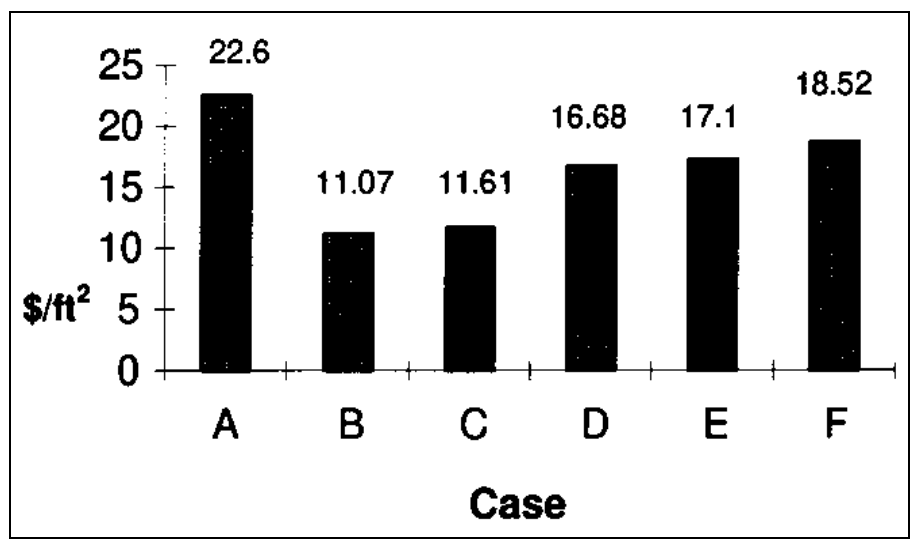

Figure 10. Installed glazing cost.



Figure 11. Ten-year life cycle cost. 


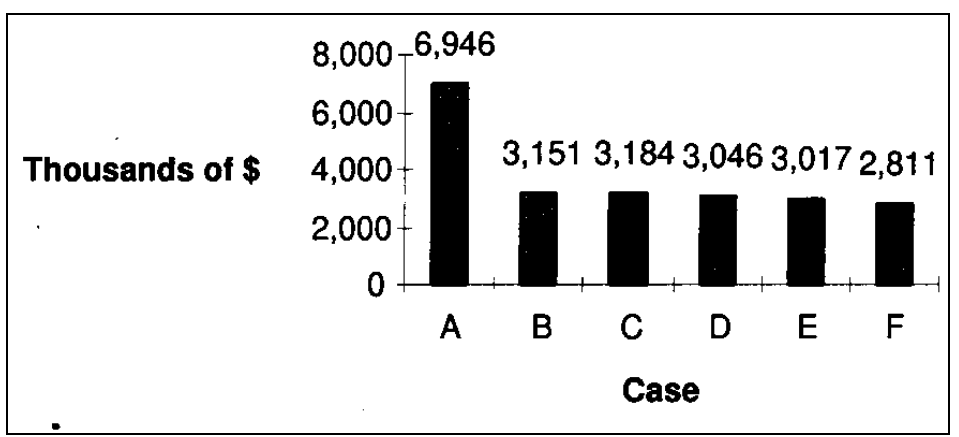

Figure 12. Twenty-year life cycle cost.

If case $F$ is chosen as the selected path, specifications that generally meet the glazing characteristics of case $F$ should be described. This allows for various products and combinations to be used in the bidding process, producing the desired results at the lowest cost.

\section{Summary of ENSAR Case Study}

Other factors to consider when evaluating from a holtic perspective include these findings:

- more effective and better quality daylighting system is likely to improve worker satisfaction, increase productivity, and reduce absenteeism

- improved glazings may result in windows that have surface temperatures closer to the indoor air than conventional glazing, improving thermal comfort and reducing energy expenditures.

Additional economic considerations include marketability and added real estate value. If the space has improved comfort, more effective daylighting, and a stronger connection to the outdoors, it is likely to rent faster. Reduced operating costs may, in part, be passed on to tenants. When the owner sells the building, wise investments in energy efficiency should bring added value to the resale of the property, and it may sell quicker. Both results benefit the owner.

In summary, glazings are important building components. As shown in this case study, the right glazing choice can save millions of dollars over the lifetime of the investment. Poor choices may not only cost more, but may also produce uncomfortable conditions. The extra time spent understanding the consequences of glazing characteristics and proper selection will produce a more efficient and higher quality building. 


\section{Window Energy Rating and Labeling}

Many windows, skylights, and glazed doors now bear energy ratings, similar to those being placed on household appliances, to assist consumers in selecting energy-efficient products. The labels have been developed by a nonprofit group, the National Fenestration Rating Council (NFRC). The NFRC also publishes the Certified Products Directory, which includes uniform U-factor listings for windows, skylights, and doors. The uniform rating system and labeling eliminates the confusion of "center glass" and "whole unit" rating scales. (When the frame area and edge of glass area are factored, the overall, whole unit Rvalue is typically 30 to 50 percent lower than center glass values.) Along with whole unit U-factors for two window sizes (2- by 4-ft for residential and 3- by 5$\mathrm{ft}$ for commercial), the listings include the number of glazing layers, airspace width, surface emissivity, and type of gas filling.

The following questions and answers, from an interview with NFRC staff, summarizes these new window energy ratings.

Q: Why are energy ratings or labels important for windows and skylights?

A: Fenestration (windows, skylights, glazed doors, etc.) can account for over 25 percent of the heating and cooling energy bills in a typical home. Designers, builders, and homeowners have never had a tool for determining or comparing the energy performances of fenestration products to assist them in their purchase decisions. Many manufacturers offer a variety of energy-efficient products but have not been able to demonstrate their superiority through comparable performance ratings.

Q: How will designers and homeowners use these energy labels?

A: Energy labels will show a variety of product performance attributes, enabling designers to compare and select products directly, based on each project's specific energy performance needs. Until now, designers have had to spend too much time trying to understand a confusing mix of rating techniques, test methods, and performance claims. A nationwide system for rating whole-product energy performance will not only give designers the energy information they seek, but will also permit direct product comparisons. 
Homeowners have faced a similar dilemma. When selecting fenestration products for a remodeling project or new construction, homeowners have had no way to compare the energy performances of two products directly. This difficulty has been compounded by the different energy rating techniques employed by the various industry segments. Window energy labels will enable consumers to compare products directly, regardless of glazing and frame type.

Q: How will the energy ratings be determined?

A: The energy ratings are determined using advanced computer tools developed in the United States and Canada, combined with standardized product performance testing. The WINDOW 4.1 program, developed at the E.O. Lawrence Berkeley National Laboratory, is one of the fundamental building blocks of the rating system. This program is used to calculate the $\mathrm{U}$-factors and solar heat gain coefficients of windows. Air leakage and other energy performance attributes are also being rated. Soon, homeowners will see two new ratings, Fenestration Heating Rating (FHR) and Fenestration Cooling Rating (FCR), which provide a comparative index of heating and cooling season energy use. The RESFEN program, also developed at Berkeley Lab, can be used to estimate the annual energy consumption and utility costs associated with a particular window type and orientation in a specific geographic location based on local utility costs.

\section{Q: Are these computer tools available to the public?}

A: Yes. These computer tools are available through the NFRC for use by building energy professionals, engineers, architects, and others. NFRC also provides detailed training for manufacturers and design professionals in the proper use of these window-related computer tools. For more information on these computer programs, contact:

National Fenestration Rating Council

1300 Spring Street, Suite 120

Silver Spring, MD 20910

Telephone: (301) 589-NFRC

Fax: (301) 589-0854

e-mail: NFRCUSA@aol.com

Web: http://eande.Ibl.gov/BTP/NFRC/nfrc.html 
Q: Who is responsible for implementing the window energy performance rating and labeling program?

A: The NFRC has developed and is implementing this rating and labeling system. NFRC is a nonprofit coalition of manufacturers, builders, state and federal energy officials, private and government laboratories, utilities, consumers, and others working together to develop a nationwide energy performance rating system that is fair, accurate, and credible. As a result of this effort, consumers across the country now have energy rating labels on windows, skylights, and glazed doors analogous to those on automobiles, appliances, and insulation.

Q: Where might I see NFRC labels referenced or used?

A: Several state building codes and other organizations with an interest in promoting energy efficiency, such as utilities, are already referencing NFRC ratings. NFRC ratings are a prerequisite for some special programs, such as low-interest financing to purchase energy efficient windows. Look for labels on products displayed in your local building materials supply store or window store. NFRC ratings are listed in the product literature you can request from many window manufacturers, or from your architect or builder.



Figure 13. Sample of NFRC rating label. 


\section{Window Checklist}

\section{Design, Specification, and Installation}

This checklist guides homeowners, architects, and builders in selecting residential windows and skylights. Selecting the right window can be difficult because of the many factors involved and the great variations in climate, utility costs, and occupant needs. Note that each entry below does not apply to all circumstances and that some general guidance may appear to be contradictory because all of the detailed conditions cannot be specified. Other local sources of information for window selection are utilities, state and local code officials, design professionals, and building materials suppliers.

\section{Insulating Value and Condensation Resistance}

- Look for NFRC U-factor ratings and labels to guide selection.

- Select double-pane windows in all climates except those in which no heating is needed. Select double- or triple-pane windows with low-e coatings and gas fills in cold climates to reduce heat losses and condensation.

- Select windows with wood, vinyl, fiberglass, or properly designed thermally broken aluminum frames in all climates where heating is needed, to reduce heat losses and condensation at frames and edges.

- Use heavy drapes, thermal shades, or thermal shutters to provide additional window insulation in cold climates.

\section{Solar Control and Ultraviolet Protection}

- Look for NFRC Solar Heat Gain Coefficient ratings and labels to guide selection. 
- Select windows with spectrally selective glazings (special tints or modified low-e coatings) to reduce solar heat gains (SHGC $<0.4$ ) while maintaining high visible transmittance (glass transmittance $>0.6$ ).

- Select tinted windows to reduce solar heat gains and control glare by lowering visible transmittance.

- Select special glazings (with plastic layers or low-e coatings) to reduce UV transmission in rooms with materials subject to fading. (If this is a critical concern, consult expert assistance.)

If shading devices are to be used to supplement the use of high-performance windows:

- Select light-colored shading devices to minimize solar heat gains.

- Select exterior shading devices to minimize the inward flow of absorbed solar heat.

- Select interior shading devices to reduce solar heat gains while providing for privacy and aesthetics, or when exterior shading devices cannot be used.

- Select horizontally oriented shading devices for south-facing windows and vertically oriented shading devices for east- and west-facing windows.

- Specify overhangs, exterior awnings, or the planting of deciduous trees and shrubs to shade south-facing windows during the summer and to allow beneficial solar heat gains during the winter

\section{Daylight and View}

- Select window size, location, and glass type to provide adequate daylight levels in each space.

- Select windows with high visible transmittances to maximize outward visibility.

- Specify window sizes and positions in walls to take advantage of desirable views. 
- Position windows away from bright external surfaces that create glare.

\section{Ventilation and Airtightness}

- Select operable windows for rooms requiring substantial ventilation during mild weather and to meet building code egress requirements.

- Select casement or awning windows to maximize effective ventilation area.

- Select awning windows to better exclude precipitation while ventilating.

- Position operable windows in opposite walls of living spaces to maximize cross-ventilation.

- Select fixed windows or windows with compression seals to minimize infiltration.

- Select windows and skylights with continuous edge seals to minimize infiltration.

- Seal and caulk around window and skylight frames and sash to reduce infiltration. Follow the manufacturer's installation instructions.

\section{Sound Control}

- Position windows away from external sources of extreme noise.

- Select double- or triple-pane windows with panes of unequal thickness, laminated glass, or gas fills to minimize noise from the exterior.

\section{Privacy, Safety, and Security}

- Select interior shading devices that obscure direct view for additional privacy.

- Check building codes on fire, wind-loading, and seismic safety before selecting and positioning windows and skylights. 
- Select laminated glass or tempered glass with screens for skylights and for windows near doors or close to the floor.

- Select windows with locks or latches that can be easily opened from the interior but cannot be opened from the exterior.

\section{Maintenance, Durability, and Lifetime}

- Check warranties for indication of durability and lifetime before selecting windows and skylights.

- Check the quality of window construction.

- Use protective paints, stains, or sealants on wood window and skylight frames or select clad wood products.

- Follow the manufacturer's instructions to maintain glazing, sash, frame, and hardware in good repair.

\section{Installation}

- Check all applicable building codes before installing windows and skylights.

- Follow the manufacturer's installation instructions carefully.

\section{Economics}

- Consider the relative effects on utility bills when selecting windows and skylights. Contact the National Fenestration Rating Council or consult energy specialists or utility representatives for estimates of the energy- and cost-savings provided by energy-efficient windows and skylights.

- Consider the effects on the resale value of a home when selecting windows and skylights.

- Check local, state, and federal energy-efficiency programs and utility energyconservation programs for economic incentives for installing energy-efficient windows and skylights. 


\section{Conclusions and Recommendations}

Selecting glazing products is not a simple task, whether for new construction or as retrofit. The plethora of choices and the wide-ranging physical and visual properties make the selection process difficult and confusing. The case studies that were evaluated demonstrate that a thorough evaluation of alternatives can entail a substantial amount of effort. The current optimization of glazing system technol ogies may be less of a technical issue than a human one.

Locating technical expertise and consultants capable of conducting a sophisticated analysis and expending the time and money for such as analysis are two of the greatest hurdles facing designers. An additional problem is that (as illustrated in the ENSAR analysis, Chapter 6), the optimal glazing solution may not have the lowest first-cost. In light of our short-term approach to building construction, selection of building products is frequently based on firstcost, regardless of long-term implications. Life-cycle costing and value engineering may be espoused, but are rarely practiced and implemented.

It is difficult to draw generalized conclusions since almost every glazing situation raises unique issues. One absolute is that single pane windows should be avoided, except in areas where no heating or cooling is required and windows are properly shaded. Low-e glazing products have become so commonplace and affordable that, in envelope-dominated buildings, they are a good investment. In situations where glazed surfaces are exposed to excessive solar radiation, selective surface glazing products should be employed. Beyond these vague recommendations, it is necessary to know the context of the problem to draw intelligent conclusions.

It should be noted that high-tech glazing products are not a panacea and cannot correct for poor building design. Shading, facade location, orientation, and quantity of glazed surfaces must be evaluated along with glazing type, as early in the building design process as possible. All variables need to be examined concurrently to derive an optimized solution. Options for the reglazing of existing buildings may be somewhat more constrained than for new buildings, but creative solutions can still significantly improve the energy performance of such buildings. 
Only through sound engineering analysis can building energy systems be optimized. The tools are available to conduct these efforts; regrettably, the time, money, and human expertise are often unavailable to conduct the analysis. Simplified analytic tools help, but complex problems still require fundamental human understanding. This primer on glazing technologies is intended to broaden the human component so that one component of the complex building task can become a more manageable problem. 


\section{Glossary}

Air leakage rating: A measure of the rate of infiltration around a window or skylight in the presence of a strong wind. It is expressed in units of cubic feet per minute per square foot $\left(\mathrm{cfm} / \mathrm{ft}^{2}\right)$ of window area or cubic feet per minute per foot ( $\mathrm{ft}^{3}$ or $\mathrm{min} / \mathrm{ft}$ ) of window perimeter length. The lower a window's air leakage rating, the better is its airtightness.

Conduction: The flow of heat through a solid material, such as glass or wood, and from one material to another in an assembly, such as a window, through direct contact.

Convection: The flow of heat through a circulating gas or liquid, such as the air in a room or the air or gas between windowpanes.

Fenestration: A window or skylight and its associated interior or exterior elements, such as shades or blinds. Refer to the American Society for Heating, Refrigeration, and Air-Conditioning's Handbook for definition.

Gas fill: A gas other than air placed between window or skylight glazing panes to reduce the $\mathrm{U}$-factor by suppressing conduction and convection.

Glazing: The glass or plastic panes in a window or skylight.

Infiltration: The inadvertent flow of air into a building through breaks in the exterior surfaces of the building. It can occur through joints and cracks around window and skylight frames, sash, and glazings.

Low-emissivity (low-e) coating: Microscopically thin, virtually invisible, metal or metallic oxide layers deposited on a window or skylight glazing surface primarily to reduce the U-factor by suppressing radiative heat flow through the window or skylight.

Radiation: The transfer of heat in the form of electromagnetic waves from one separate surface to another. Energy from the sun reaches the earth by radiation, and a person's body can lose heat to a cold window or skylight surface in a similar way. 
R-value: a measure of the resistance of a material or assembly to heat flow. It is the inverse of the $U$-factor $(R=1 / U)$ and is expressed in units of $\mathrm{hr} \Leftrightarrow \mathrm{ft}^{2} \Leftrightarrow \sim^{\circ} \mathrm{F} / \mathrm{Btu}$. A high window $\mathrm{R}$-value has a greater resistance to heat flow and a higher insulating value.

Shading Coefficient (SC): A measure of the ability of a window or skylight to transmit solar heat, relative to that ability for $1 / 8$-in. clear, doublestrength, single glass. It is equal to the Solar Heat Gain Coefficient multiplied by 1.15 and is expressed as a number (without units) between 0 and 1. The lower a window's Shading Coefficient, the less solar heat it transmits and the greater its shading ability.

Solar Heat Gain Coefficient (SHGC): The fraction of solar radiation admitted through a window or skylight, both directly transmitted and absorbed, and subsequently released inward. The Solar Heat Gain Coefficient has replaced the shading coefficient as the standard indicator of a window's shading ability. It is expressed as a number (without units) between 0 and 1. The lower a window's Solar Heat Gain Coefficient, the less solar heat it transmits and the greater its shading ability.

Spectrally selective glazing: A specially engineered low-e coated or tinted glazing that blocks out much of the sun's heat while transmitting substantial daylight.

U-factor (U-value): A measure of the rate of heat flow through a material or assembly. It is expressed in units of $\mathrm{hr} \mathrm{ft}^{2} \sim^{\circ} \mathrm{F} / \mathrm{Btu}$ or $\mathrm{W} / \mathrm{m}^{2} \sim^{\circ} \mathrm{C}$. Window manufacturers and engineers commonly use the U-factor to describe the rate of nonsolar heat loss or gain through a window or skylight. Lower window $\mathrm{U}$-factors have greater resistance to heat flow and better insulating value.

Visible transmittance: The percentage or fraction of visible light transmitted by a window or skylight. 


\section{Appendix A: Information Source List}

The following resources provide more information on energy-efficient windows.

American Architectural Manufacturers Association (AAMA)

2700 River Road, Suite 118

Des Plaines, IL 60018

(708) 202-1350

Developed a testing procedure (AAMA 1503) for measuring the thermal transmission properties of aluminum-, vinyl-, and wood-framed windows.

American Society of Heating, Refrigerating, and Air-Conditioning Engineers 1791 Tullie Circle, NE

Atlanta, GA 30329

(404) 636-8400

ASHRAE's (1993) "Handbook of Fundamentals" contains tables citing heat transfer, light transmittance, and shading properties for various window types and materials.

E.O. Lawrence Berkeley National Laboratory

1 Cyclotron Road, Mailstop 90-1070

Berkeley, CA 94720

(510) 486-6467 
WINDOW 4.1 (1994) is a computer program for calculating the thermal and optical properties of a window.

National Fenestration Rating Council (NFRC)

962 Wayne Avenue, Suite 750

Silver Spring, MD 20910

(301) 589-6372

Devel oped the "Procedure for Determining Fenestration Product Thermal Properties" (NFRC 100-91). These procedures are now being used in NFRC's window certification and efficiency labeling programs, which have already been adopted by three states. Also published a "Certified Products Directory."

National Wood Window and Door Association

1400 East Touhy Avenue

Des Plaines, IL 60018-3305

(708) 299-5200

Issues seals of approval for manufacturers of wood-framed windows.

U.S. Department of Energy (DOE)

Building Systems and Materials Division

EE-421

1000 Independence Avenue, SW

Washington, DC 20585

(202) 586-9214

Developed the WINDOW computer program, which aids window manufacturers and building designers in optimizing the thermal and daylighting performance of window systems. For their certification and 
labeling programs, the NFRC uses the WINDOW computer program and U.S. Department of Energy-supported research and testing to determine the thermal and optical properties of windows.

Vinyl Window and Door Institute

355 Lexington Avenue

New York, NY 10017

(212) $351-5400$

Developed performance standards and certification program for manufacturers of vinyl-framed windows.

For more information on energy efficiency topics, contact:

The Energy Efficiency and Renewable Energy Clearinghouse (EREC)

P.O. Box 3048

Merrifield, VA 22116 (800) DOE-EREC (363-3732)

Fax: (703) 893-0400

BBS: (800) 273-2955 


\section{Appendix B: Recommended Reading List}

\section{Publications}

“Low-E Glass-Why the Coating Is Where It Is," Energy Design U pdate, pp 5-7, March 1990.

“No Pane, No Gain (Window Technology: Part One),” Popular Science, pp 92-98, J une 1993.

“Through the Glass Darkly,” Popular Science, pp 80-87, J uly 1993.

"Windows as Luminaires," Center for Building Science News, E.O. Lawrence Berkeley National Laboratory, pp 6-7, Spring 1996.

"Glazing Design Handbook for Energy Efficiency," G. Franta and K. Anstead, ENSAR Group, Inc. (unpublished).

“Double Pane Window Study," B. Chorpening, R. Liesen, BLAST Support Office, University of Illinois Department of Mechanical and Industrial Engineering, Urbana IL, August 1995.

The Passive Solar Energy Book, Edward Mazria, Rodale Press, [author to provide City and State] 1979.

Sunlighting as a Formgiver for Architecture, William Lam, Van Nostrand Reinhold, 1986.

\section{Internet Sources}

Title: Energy Efficient Windows

Date: October 1994

Written by: National Renewable Energy Laboratory

For:U.S. Department of Energy

Distributed by: Energy Efficiency and Renewable Energy Clearinghouse

Document No.: DOE/CH10093-290 FS 216 
Location: http://www.nrel.gov/documents/erec_fact_sheets/sp-6299.pdf

Title: $\quad$ Advances in Glazing Materials for Windows

Date: November 1994

Written by: National Renewable Energy Laboratory

For:U.S. Department of Energy

Distributed by: Energy Efficiency and Renewable Energy Clearinghouse

Document No.: DOE/CH10093-332 FS 219

Location: http://www.nrel.gov/documents/erec_fact_sheets/sp-6803.pdf

Title: Selecting Windows for Energy Efficiency

Date: J anuary 1996

Written by: LBL - DOE Windows and Glazings Research Program

For:U.S. Department of Energy

Distributed by: Internet

Location: http://eanda.Ibl.gov/BTP/DOE/sel_wind.html

Title: Window Energy Rating and Labeling

Date: J anuary 1996

Written by: LBL-DOE Windows and Glazings Research Program

For:Department of Energy

Distributed by: Internet

Location: http://eande.lbl.gov/BTP/DOE/ 
Title: Window Checklist

Date: J anuary 1996

Written by: LBL-DOE Windows and Glazings Research Program

For:U.S. Department of Energy

Distributed by: Internet

Location: http://eande.lbl.gov/BTP/DOE/ 


\section{USACERL DISTRIBUTION}

Chief of Engineers

ATTN: CEHEC-IM-LH (2)

ATTN: CEHEC-IM-LP (2)

ATTN: CECC-R

ATTN: CERD-L

ATTN: CERD-M

ATTN: CEMP-ET (2)

US Army Engr District

ATTN: Library (42)

US Army Engr Division

ATTN: Library (8)

Defense Tech Info Center 22304

ATTN: DTIC-O (2) 